\title{
High-resolution mini-seismic methods applied in the Mont Terri rock laboratory (Switzerland)
}

\author{
Kristof Schuster $^{1} \cdot$ Florian Amann ${ }^{2} \cdot$ Salina Yong ${ }^{2,3} \cdot$ Paul Bossart $^{4}$. \\ Peter Connolly ${ }^{5}$
}

Received: 1 June 2016/Accepted: 9 December 2016/Published online: 22 February 2017

(C) The Author(s) 2017. This article is published with open access at Springerlink.com

\begin{abstract}
We present several mini-seismic methods developed and applied in recent years in the Mont Terri rock laboratory. All these applications aimed at correlating and interpreting seismically derived parameters with relevant rock-mechanical parameters and findings. The complexity of the local site setting always required very high spatial and parameter resolution. Both, seismic $\mathrm{P}$ - and S-wave velocities and dynamic elastic parameters, such as the dynamic Poisson's ratio $v_{\text {dyn }}$ and the Young's modulus $E_{\mathrm{dyn}}$, are used to characterise the Opalinus Clay under real in situ conditions. We were able to establish a correlation between static and dynamic elastic Young's moduli. We describe the extremely large, small-scale variability of seismic parameters normal and parallel to the bedding plane orientation and address the question of fracture detection. We also present examples of the characterization of excavation-damaged zones with
\end{abstract}

Editorial handling: P. Bossart and A. G. Milnes.

This is paper \#10 of the Mont Terri Special Issue of the Swiss Journal of Geosciences (see Bossart et al. 2017, Table 3 and Fig. 7).

Kristof Schuster

kristof.schuster@bgr.de

1 Federal Institute for Geosciences and Natural Resources BGR, Stilleweg 2, 30655 Hannover, Germany

2 Earth Science Department, Swiss Federal Institute of Technology, Sonneggstrasse 5, 8092 Zurich, Switzerland

3 Present Address: Knight Piésold Ltd., Suite 1400, 750 West Pender, Vancouver, BC V6C 2T8, Canada

4 Federal Office of Topography Swisstopo, Seftigenstrasse 264, 3084 Wabern, Switzerland

5 Rock Mechanics Team, CHEVRON, Chevron Exploration Technology Company, 1500 Louisiana Street, Houston, TX 77002, USA seismic parameters, including extent as well as degree of damage, and compare these to geological and structural mapping. The evolution of borehole-disturbed zones (BdZ) was deduced from repeating high-resolution borehole measurements. Finally, we quantify seismic anisotropy at dimensions between several $\mathrm{cm}$ and tens of $\mathrm{m}$.

Keywords Seismic velocities - Dynamic and static elastic parameters - Seismic anisotropy - Fracture detection . $\mathrm{EDZ} \cdot \mathrm{BdZ} \cdot$ Opalinus Clay $\cdot$ Nuclear waste disposal

\section{Introduction}

The term "high-resolution mini-seismic methods" (HRMSM) comprises all seismic, sonic, and ultrasonic in situ methods that the German Federal Institute for Geosciences and Natural Resources (BGR) has developed and continues to develop for underground investigations. This involves a broad variety of seismic, sonic, and ultrasonic methods with high spatial resolution in the centimetre to dekametre range associated with a high dynamic-parameter resolution. We applied all of these methods at the Mont Terri rock laboratory. Figure 1 shows the location of the laboratory within the Opalinus Clay Formation and its complex structural context. The lithological and structural overview of the Opalinus Clay at Mont Terri, its mineralogy, and key parameters is given in Bossart et al. (2017a).

The Opalinus Clay at the Mont Terri rock laboratory can be differentiated into three facies (shaly, sandy, and carbonate-rich sandy), all of which possess different petrophysical properties (Bock 2002; Bossart and Thury 2008). For example, each facies has a pronounced bedding-related anisotropy resulting in transverse isotropic (TVI) seismic parameters and significant small-scale variations of rock 
NNW

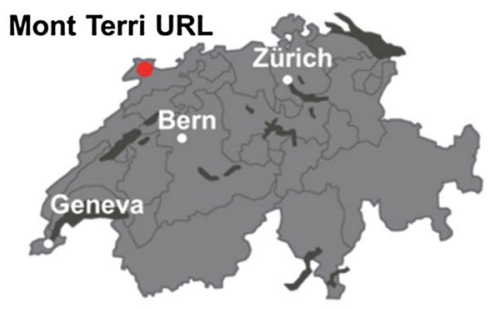

m. a.s. I

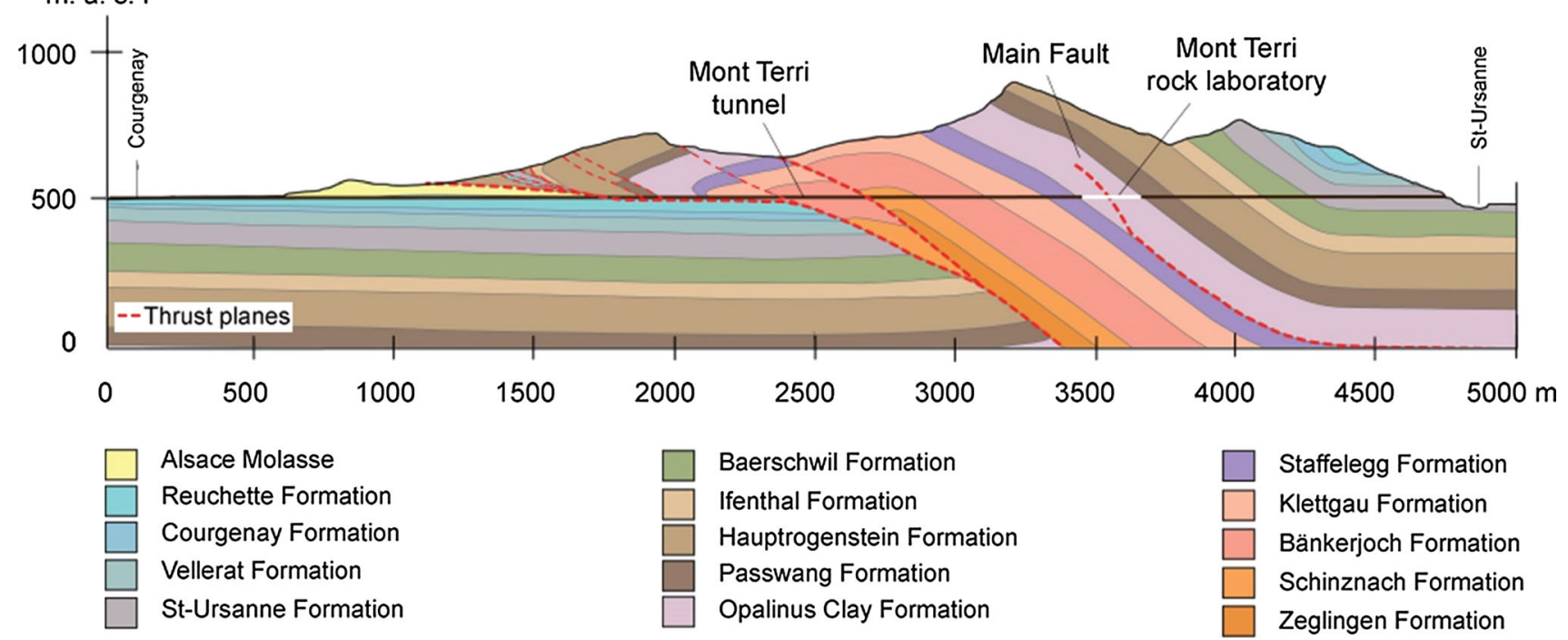

Fig. 1 The Mont Terri rock laboratory, located in the Canton of Jura, northwestern Switzerland, lies in the Opalinus Clay. The geological setting of the Opalinus Clay and the mini-seismic experiment sites in the rock laboratory are shown in Bossart et al. (2017a)

properties of different intensities at several sites due to small-scale heterogeneities. To address these inherent complexities with an appropriate spatial resolution, we need high-resolution mini-seismic measurements (MSM).

Since 1996, BGR has carried out MSM in the Mont Terri rock laboratory in close cooperation with experiment partners. Most of the experiments were closely linked to questions concerning geological, geotechnical, or rockmechanical questions. The mutual inspiration and open discussions between experiment partners has enabled comprehensive interpretation of the mini-seismic results and furthered continuous development of MSM. Out of all the numerous results achieved during the last years, this present contribution focuses on the following issues:

1. Seismic and dynamic elastic parameters,

2. Small-scale variability of the Opalinus Clay,

3. EDZ and fracture detection,

4. BdZ characterization, and

5. Seismic anisotropy measured at different scales.

Other aspects appropriate for study using our MSM methods and concepts, such as detection and characterization of fault structures, seismic long-term monitoring to characterise evolution of the EDZ (generation and self- sealing), and evolution of backfill material (sand-bentonite), are presented in other papers in this issue (e.g., Jaeggi et al. 2017; Wieczorek et al. 2017).

Our main objective here is to draw attention to in situ, high-resolution mini-seismic methods and their ability to provide real in situ results for a better understanding of in situ rock-mechanical properties. In addition, combining results from MSM with those derived under laboratory conditions (mostly static tests) on cores can improve our understanding and interpretation of rock-mechanical modelling. Bossart et al. (2017a), this issue) present an overview of the experiments and sites where the MSM have been applied.

\section{Methods}

The in situ investigations were conducted in single boreholes, between boreholes, non-destructively along and between drifts, and in combinations of these situations. In addition, we used a wide range of seismic monitoring tasks and targeted repetition of measurements to assess evolution of the rock mass with respect to seismic characteristics. The interdependence/applicability of the methodologies is given in Fig. 2. We consider the MSM to be a suitable tool to bridge 
Fig. 2 BGR mini-seismic methods (MSM) according to their application: (1) single hole, (2) multi-hole, (3) shaft/drift, (4) borehole-drift, (5) special (monitoring and targeted repetition of measurements)

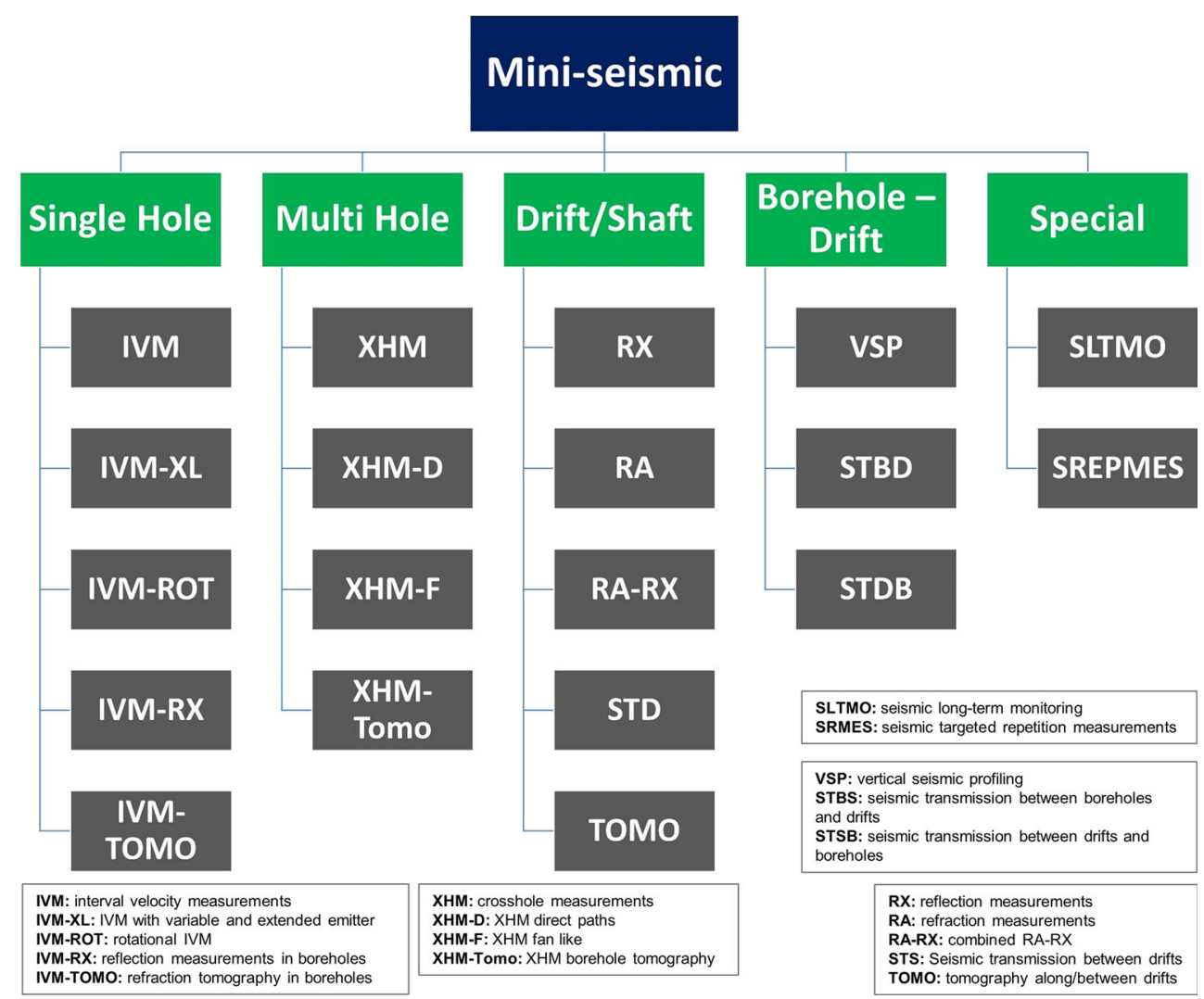

in situ rock-mechanical results, results from laboratory testing, and results stemming from thermo- and hydro-mechanical modelling. Results from MSM closely sample the actual local in situ conditions. In particular, signals from disturbances caused by the borehole, such as identified BdZ, can be corrected for or, with wide enough separation between emitters and receivers, even neglected. Due to local conditions (stress field, damage, pore space connectivity, ventilation, degree of saturation) rock parameters change with time. Therefore, any measurement, especially in the nearfield of an excavation, is a snapshot in time. Thus, the results reflect the state of petrophysical parameters at that specific time. To quantify time-dependent processes in the targeted rock, we repeat a set of measurements or install automatic long-term monitoring with a fixed emitter-receiver system (e.g., Wieczorek et al. 2017).

The frequency range of BGRs mini-seismic data lies in the general range $0.1-100 \mathrm{kHz}$, depending on local site situations and rock properties. This spans three different frequency bands, namely seismic, sonic, and lower ultrasonic frequencies. In several applications these bands overlap, but the principles are the same for each frequency band. To simplify discussions, we use the term "mini-seismic" or simply "seismic" to cover all these applications.

The basic principle of the mini-seismic measurements is shown schematically in Fig. 3. For all methods, a seismic wave-field is emitted into the rock at a certain location, which is then recorded with seismic receivers at several other locations, and subsequently analysed. We use various piezoelectric transducers or a selection of mechanical impulse sources (emitters). Seismic wave-field receivers are always piezoelectric transducers registering both 1and/or 3 components. Typically, we installed between seven (e.g., borehole tools) and 160 (e.g., sensors glued along drifts) receivers for a single shot (excitation). Distances between emitters and receivers range from 5 to $80 \mathrm{~cm}$ (borehole tools) and from 5 to $100 \mathrm{~m}$ for miniseismic transmission measurements between drifts. Generally, we analyse refracted, transmitted, and partly reflected P- and S-wave phases. For recording, we use a modified electronic laboratory transient recorder and amplifier system comprising up to 160 channels (Schuster 2002).

For each situation, we choose an appropriate method (Fig. 2) depending on the scientific questions and the desired spatial and parameter resolution. All measurements are necessarily a compromise between spatial and seismicparameter resolution (Schuster 2012). Generally, as distances between emitters and receivers increase, the spatial resolution decreases. For applications at the Mont Terri rock laboratory, the centre frequency range for the emitters lies in general between 1 and $100 \mathrm{kHz}$, corresponding to wavelengths between $270 \mathrm{~cm}$ (e.g., measurements between drifts) and $2.7 \mathrm{~cm}$ (e.g., measurements in boreholes) for 
(a)

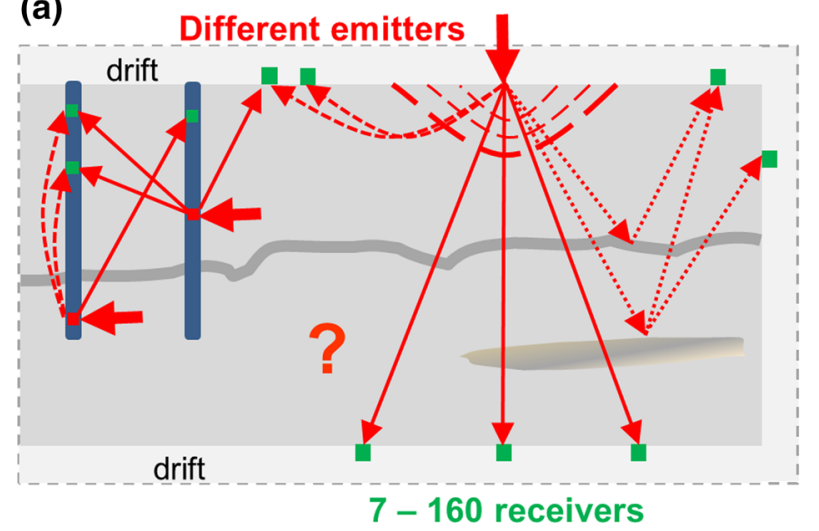

(b)

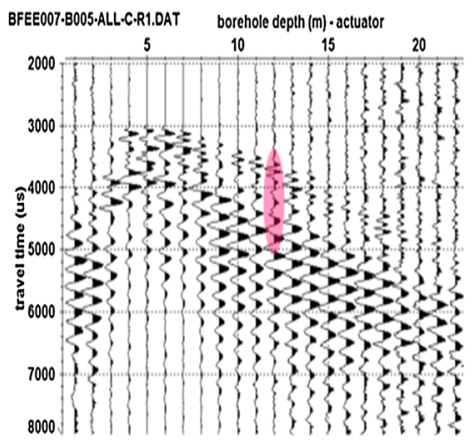

(c)

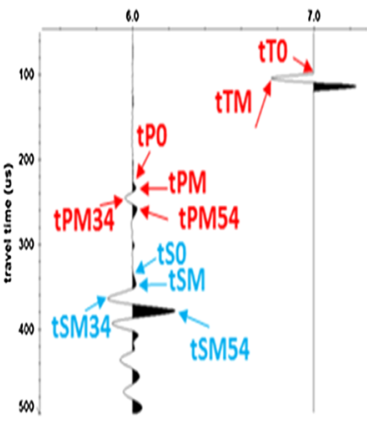

Fig. 3 Basic principle of MSM. a Emitted wave-field represented by seismic ray-paths. b Derived seismic section with a marked seismic trace, which is used for the extraction of seismic attributes. $\mathbf{c}$ Marked seismic attributes, which are used for seismic parameter calculation

P-waves and between 140 and $1.4 \mathrm{~cm}$ for S-waves. For this appraisal we chose a typical mean $\mathrm{P}$-wave velocity of $2700 \mathrm{~m} / \mathrm{s}$ and a $v_{\mathrm{p}} / \mathrm{v}_{\mathrm{s}}$ ratio of 1.92 for Opalinus Clay. As a first approximation, we assume two-dimensional wave propagation in a plane containing the emitter and the line of receivers. All the boreholes needed or used for our investigations at the Mont Terri rock laboratory were drilled with air. The most common diameters for our boreholes were 86,101 and $131 \mathrm{~mm}$. The lengths of the different boreholes ranged from 3 to $32 \mathrm{~m}$.

\section{Results from in situ applications of mini-seismic methods}

We present representative results from mini-seismic measurements performed in the framework of experiments that provided data relevant to answer questions on rock mechanics, lithology, and structure.

\subsection{Seismic and dynamic elastic parameters}

Using seismic attributes determined from phase correlations in seismic sections, such as travel times, amplitudes, and polarities of different $\mathrm{P}$-wave and S-wave phases, we calculated appropriate seismic parameters for each trace (Fig. 3c). In general, the boreholes used for our measurements are oriented perpendicular, parallel, or at $45^{\circ}$ with respect to the bedding plane. Therefore, the measurements record a specific transversely isotropic (TVI) behaviour of the rock and the evaluation of the dynamic elastic parameters along these orientations is done by applying isotropic formulas (no TVI correction) to account for the orientation. Additionally, no differentiation between quasi and "pure" Por S-waves is made, due to the short travel paths and the specially selected orientations of boreholes or profile layouts with respect to orientation of the bedding plane. Knowing the coordinates of the emitter and receiver locations, we calculated the P-wave velocity $\left(\mathrm{v}_{\mathrm{p}},\right)$ and $\mathrm{S}$-wave velocity $\left(\mathrm{v}_{\mathrm{s}}\right)$. Furthermore, we determined the $\mathrm{v}_{\mathrm{p}} / \mathrm{v}_{\mathrm{s}}$ ratio, the absolute and normalised amplitudes of several phases, the frequency content, and the dynamic Poisson's ratio $v_{\mathrm{dyn}}$. By using a site-specific value for the mean bulk density with respect to the three facies, we can also calculate additional dynamic elastic parameters such as Young's modulus $\mathrm{E}_{\mathrm{dyn}}$, shear modulus $\mathrm{G}_{\mathrm{dyn}}$, and bulk modulus $\mathrm{K}_{\mathrm{dyn}}$. Thus, we obtain a set of parameters useful to characterise the rock mass and, in certain cases, structural information that can, for example, help differentiate lithologies.

We used the following formulas to derive the parameters mentioned above and also the seismic and dynamic elastic parameters that we will discuss below.

Seismic velocities: $v=\frac{l}{t}(v$ stands for apparent P-wave, or S-wave velocities, in certain cases apparent velocities).

Dynamic elastic Poisson's ratio: $v_{\mathrm{dyn}}=\frac{v_{p}^{2}-2 v_{s}^{2}}{2\left(v_{p}^{2}-v_{s}^{2}\right)}$.

Dynamic elastic Youngs's modulus: $\mathrm{E}_{\mathrm{dyn}}=2 \cdot \rho$. $v_{s}^{2}\left(1+v_{d y n}\right)$.

Dynamic elastic bulk modulus: $\mathrm{K}_{\mathrm{dyn}}=\rho \cdot\left(v_{p}^{2}-\frac{4}{3} v_{s}^{2}\right)$.

Dynamic elastic shear modulus: $\mathrm{G}_{\mathrm{dyn}}=\rho \cdot v_{s}^{2}$.

Seismic anisotropy coefficient: $A v=\frac{\left(v_{\max }-v_{\min }\right)}{v_{\min }}$.

Average seismic velocity anisotropy: $A v_{p}=\frac{v_{\text {max }}-v_{\text {min }}}{v_{p \operatorname{mean}}}$. $100 \%$. Furthermore, distance $l$, travel time $t$ and bulk density $\rho$.

At several IVM tests, we registered velocity dispersion in the range $20-120 \mathrm{kHz}$. In the present contribution we will not further discuss this frequency dependence of seismic velocities and, consequently, of dynamic elastic parameters. Most of the IVM were performed with $50 \mathrm{kHz}$, which was found to be a good compromise between spatial resolution and coverage. 
In the HE-B heater experiment (formerly HE) at the Mont Terri rock laboratory, nine vertical boreholes were drilled around the central vertical borehole where the heater was placed (Göbel et al. 2007). A section of these boreholes with diameters of $86 \mathrm{~mm}$ were used for dilatometer measurements and IVM. Here, we used a 4-channel ultrasonic borehole probe. The principle of IVM is described briefly in Sect. 3.2 and in more detail in Schuster et al. (2001) and Schuster (2012). Figure 4a-e presents the derived $\mathrm{v}_{\mathrm{p}}$, normalized amplitudes of first-arrival $\mathrm{P}$-wave phases, and the dynamic elastic parameters $v_{\text {dyn }}$ and $E_{\text {dyn }}$ obtained with IVM in borehole BHE-25 (location: HE niche, borehole drilled $-90^{\circ}$ down into the floor, approximately $45^{\circ}$ with respect to the bedding planes.

Three apparent $\mathrm{v}_{\mathrm{p}}\left(\right.$ app. $\left.\mathrm{v}_{\mathrm{p}}\right)$ for receivers $\mathrm{R} 1(10 \mathrm{~cm}), \mathrm{R} 2$ $(20 \mathrm{~cm}), \mathrm{R} 3(30 \mathrm{~cm})$ and the $\mathrm{BdZ}$ corrected $\mathrm{v}_{\mathrm{p} \text {-corBdZ }}$ are plotted on Fig. 4a. The differences between the three app. $v_{p}$ indicate the existence of a BdZ (see also Sect. 3.4). The $\mathrm{v}_{\mathrm{p} \text {-corBdZ }}$ allows us to capture the rock parameters that are not affected by the BdZ (i.e. to "look behind the BdZ"). Furthermore, the reduced $\mathrm{v}_{\mathrm{p}}$ and normalised amplitudes obtained are below average for features that extend up to $2.4 \mathrm{~m}$ and are attributed to the EDZ. The distinct $\mathrm{v}_{\mathrm{p}}$ peaks at 2.9 and $5.7 \mathrm{~m}$ and the variations in between are interpreted as sandy lenses and structural changes.

To determine dynamic elastic parameters, we used R2 data (distance of $20 \mathrm{~cm}$ between emitter and receiver), since the vertically polarized Sv-wave phase could be best resolved for this subset. The Sv-wave phases for R3 data could not be distinctly identified over the complete section. Where direct comparison was possible between R2 and R3 Sv-phases, it was found that R2 and R3 parameters are very similar. Note that at some locations these R2 data may be slightly influenced by the BdZ. Calculation of the dynamic elastic parameters used an isotropic approach accounting for the measurements being oriented towards bedding. The derived $v_{\text {dyn }}$ varies between 0.3 and 0.38 along the profile whilst $\mathrm{E}_{\mathrm{dyn}}$ shows a gradual increase from 6 to $10 \mathrm{GPa}$, except at the two peaks around 2.9 and $5.7 \mathrm{~m}$. These two peaks correspond to the $\mathrm{v}_{\mathrm{p}}$-peaks associated with sandy lenses and structural changes mention above. Young's moduli derived from dilatometer measurements at four depths are plotted on Fig. 4d (blue dots, right y-axis) and are considered to represent static values. Similarly to the dynamic values they increase gradually from 3.18 to 3.97 GPa. Comparison between dilatometer and seismically derived data at these depths result in $\mathrm{E}_{\mathrm{dyn}}=(2.29$, ..., 2.49) $\times \mathrm{E}_{\text {stat }}$. These correlation factors (which are labelled in Fig. 4d) are close to the factor 2.5 found by Corkum (2006) at another location in the laboratory. Corkum (2006) derived $\mathrm{E}_{\text {stat }}$ from core-sample laboratory tests and compared these results with $\mathrm{E}_{\mathrm{dyn}}$ derived from IVM performed in the same borehole (Schuster 2002).

The dynamic and static E-modulus correlation factor of 2.3-2.5 yields important bounds for the determination of dynamic elastic parameters under in situ conditions with MSM and is crucial to account for when characterising the rock mass.

The main advantages of using MSM for the determination of dynamic elastic parameters can be summarised as follows:

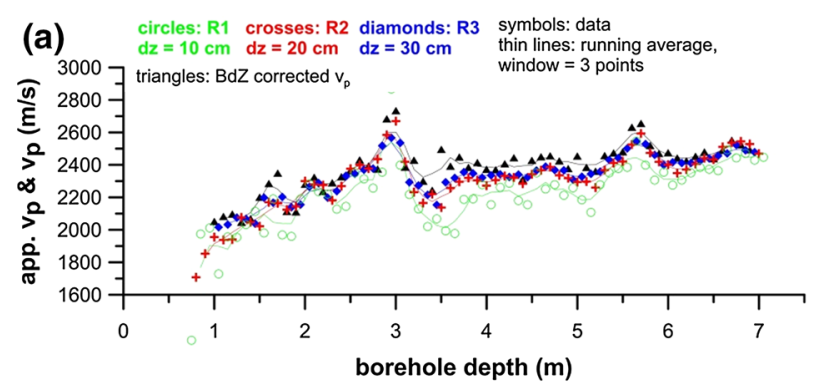

(b)

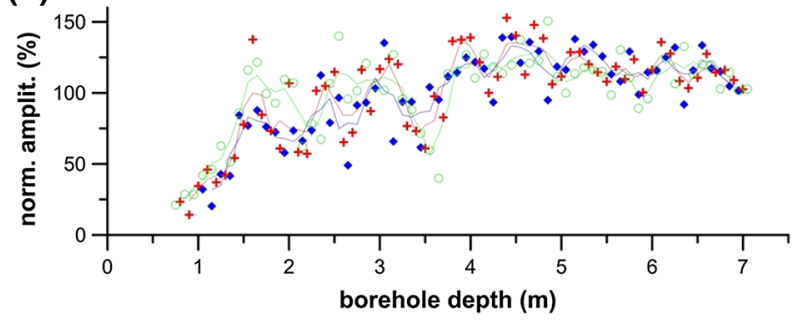

Fig. 4 Seismic parameters derived with IVM in borehole BHE-B25. a Apparent and BdZ-corrected $\mathrm{v}_{\mathrm{p}}$. b Normalised P-wave onset amplitudes. c Dynamic Poisson's ratio (R2-data). d Dynamic Young's (c)

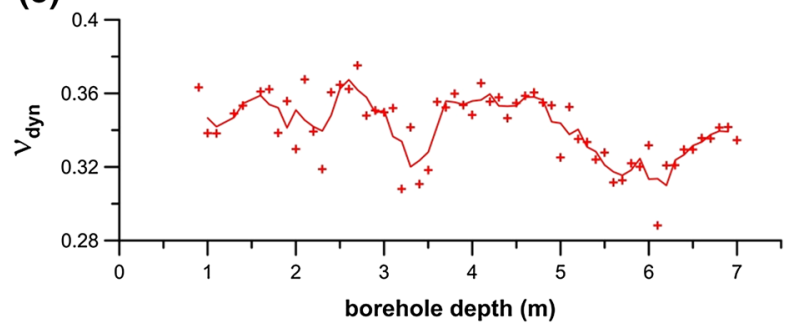

(d)

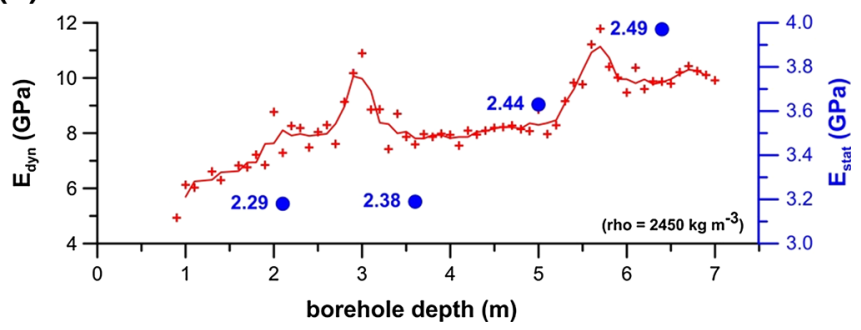

(left y-axis) and static Young's moduli derived with dilatometer tests (right y-axis). The labels represent the correlation factors between $\mathrm{E}_{\text {stat }}$ and $\mathrm{E}_{\mathrm{dyn}}$ 
- Dynamic elastic parameters are measured in situ under real site conditions, without taking the risk of specimen alteration during extraction, transport and/or conditioning, especially when the technique chosen provides insight into the properties of the undisturbed rock mass,

- The dynamic Poisson's ratio is, for example when using IVM data, available along the complete borehole length in increments of $5 \mathrm{~cm}$,

- Mini-seismic excitations induce only small displacements of the rock mass and avoid risk of producing non-linear elastic effects that could lead to inaccurate results,

- Continuous borehole measurement avoids missing relevant parts for the characterisation associated with the rock heterogeneity when compared to a selective core-sampling method. Especially in regions with core loss, it is a simple way to obtain dynamic elastic parameters, and

- As a by-product of continuous IVM, cracks can be detected in the rock mass. In many cases a clear correlation between cracked cores and seismic-parameter anomalies (reduced $\mathrm{v}_{\mathrm{p}}, \mathrm{v}_{\mathrm{s}}$ and amplitudes) at the borehole wall at corresponding depths can be observed.

In summary, the results discussed in this section show that MSM provide a large number of attributes and parameters for the seismic and dynamic elastic characterisation of the Opalinus Clay. Furthermore, we could establish a relationship between static and dynamic elastic parameters.

\subsection{Small-scale heterogeneity of the Opalinus Clay}

Excavation work and analyses of core samples have exposed the existence of a pronounced variability in rock parameters due to heterogeneities in the Opalinus Clay at the Mont Terri rock laboratory. Boreholes are indispensable to characterise these variations quantitatively using seismic and dynamic elastic parameters with very high spatial and parameter resolution, even when they alter the rock mass (Schuster 2012). To enable a high spatial resolution in the $\mathrm{cm}$ range, BGR developed ultrasonic borehole probes. These borehole probes use piezoelectric transducers serving as emitters or receivers of ultrasonic waves at distances of $5 \mathrm{~cm}$ (8KUBS-05, Fig. 5b) and $10 \mathrm{~cm}$ (8KUBS-10) between emitter (S1) and the first receiver (R1). Between the receivers (R1-R7) the distances are $5 \mathrm{~cm}$ (8KUBS-05) or $10 \mathrm{~cm}$ (8KUBS-10). The piezoelectric transducers are particularly sensitive to ultrasonic wave energy emerging with vertical or nearvertical incidence angles. Therefore, mainly $\mathrm{P}$-waves and $\mathrm{Sv}$-waves are recorded, no horizontally polarised S-waves. The transducers are coupled pneumatically against the borehole wall. Outside the boreholes we use 3-component piezoelectric transducers to capture the ultrasonic wavefield with three components. The probes can be applied in boreholes with diameters starting from $86 \mathrm{~mm}$. Greater diameters can be used by assembling temporarily appropriate adapters. The largest diameters used for IVM in the Mont Terri rock laboratory were $300 \mathrm{~mm}$ (location: SB niche, borehole orientation $-90^{\circ}$ down). Using a special adapter, a horizontal borehole with a diameter of $740 \mathrm{~mm}$ (Alveole) was measured in the French Meuse/HauteMarne Underground Research Laboratory. Both types of borehole probes, and the associated software tools, allow us to characterise the local rock mass to a very high spatial and parameter resolution. The principle is shown in Fig. 5a. The emitted seismic-wave energy from source $\mathrm{S} 1$ is represented by seismic rays traveling along the borehole wall as refracted waves with different penetration depths. These depths depend on degree of disturbance in the borehole wall. Figure $5 \mathrm{c}$ depicts a typical common shot (CSP) section with the correlated P- and Sv-wave phases. The exact distribution of travel paths depends upon the shape of the BdZ. Our IVM enables us to investigate behind the $\mathrm{BdZ}$ into the undisturbed rock (see Sect. 3.4). For several CSP data sets, we performed finite-difference ray-tracing simulations to confirm the wave propagation ( $\mathrm{P}$ - and $\mathrm{Sv}$-waves with refracted propagation paths). After the probe is moved through the borehole, recording incremental measurements in steps of 5 or $10 \mathrm{~cm}$ as CSP-sections, the data are re-sorted into seven constant-offset (COF) sections. Figure 5d (borehole BEZ-B03, see Sect. 3.3) shows an example for a distance of $20 \mathrm{~cm}$ between source and receivers. In such COF sections, extraction of seismic attributes, estimation, and presentation of seismic parameters are very beneficial.

We installed a high-resolution photo camera on both sonic probes. Taking photographs of details of the borehole wall at every shot point is part of any IVM. These photographs support the interpretation of IVM data. The camera can also be used in selected boreholes without performing IVM. Figure 6a illustrates the principle. The $86 \mathrm{~mm}$ diameter borehole wall is unrolled and covers an area $58 \mathrm{~mm}$ by $63 \mathrm{~mm}$. Figure $6 \mathrm{~b}$ shows a photograph taken in the shaly facies, containing a single tectonic thrust. Figure $6 \mathrm{c}$ belongs to the carbonate-rich sandy facies, where in the central part breakouts can be identified at the borehole wall. Figure $6 \mathrm{~d}$ shows the sandy facies, where sedimentary bioturbation structures are visible.

On several occasions, detailed and well-resolved smallscale sedimentary and tectonic structures could be captured with the help of the borehole camera photos of unrolled borehole walls. Figure 7 shows a small detail of a disturbed zone ca. $6 \mathrm{~m}$ behind the Main Fault at a depth of $12.15 \mathrm{~m}$ in borehole BSO-37. This borehole was drilled from the 
(a)

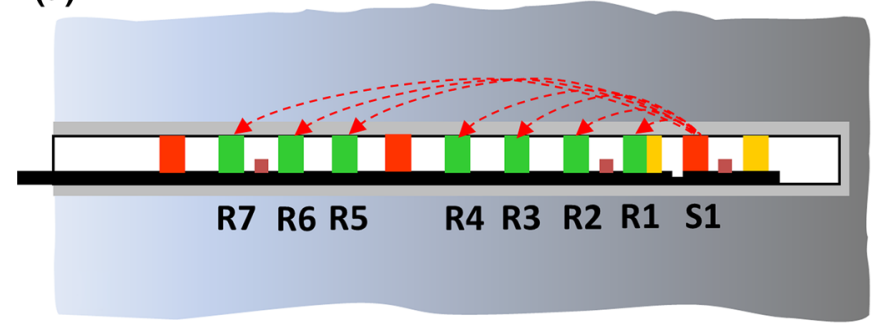

(b)

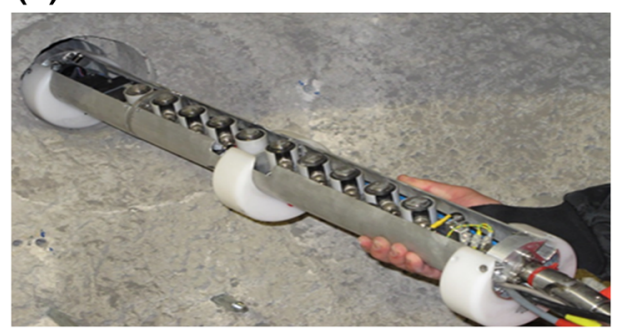

(c)

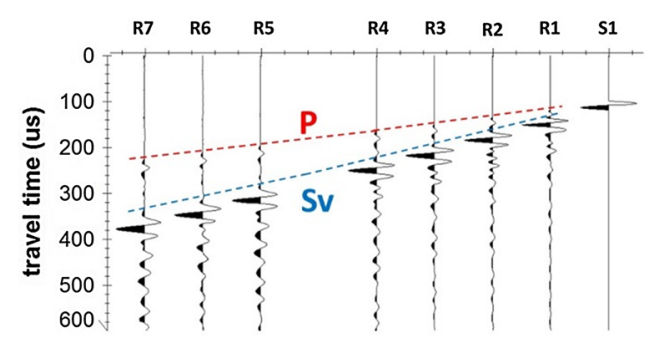

Fig. 5 Principle of seismic interval-velocity measurements (IVM). b BGR 8-channel ultrasonic borehole probe (8KUBS-05). a Principle of IVM with simplified ray-paths. The simultaneous full wave recording at seven receivers $(5-80 \mathrm{~cm})$ allows characterisation of

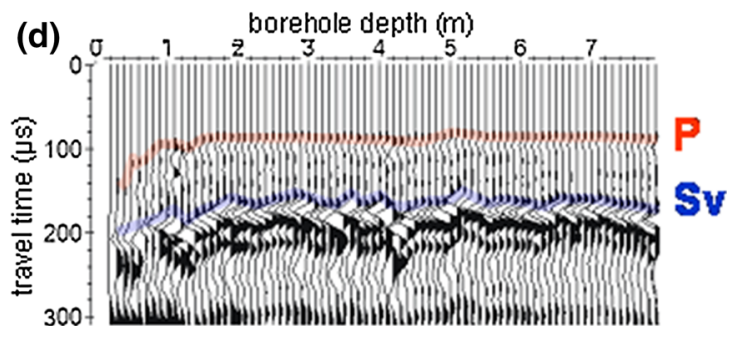

both the BdZ and the host rock. c Single seismic record, excitation signal (S1) and seven seismic traces with marked onsets of P- and Svwave phases (receivers R1-R7). d Seismic COF section for one receiver distance $(\mathrm{R} 2,20 \mathrm{~cm})$ with marked $\mathrm{P}$ - and Sv-onsets
Fig. 6 a Principle of IVM measurements with the 8KUBS borehole camera. Details of the borehole wall captured in an $86 \mathrm{~mm}$ diameter borehole covering an area of $58 \mathrm{~mm}$ by $63 \mathrm{~mm}$ of the unrolled borehole wall; examples: b shaly facies from MI niche, borehole BSO37 at a depth of $11.65 \mathrm{~m}$, oriented normal to bedding with an azimuth $330^{\circ}$, dip $-40^{\circ}$ downwards; c carbonate-rich sandy facies from MI niche, borehole BDM-B2 at a depth of $9.25 \mathrm{~m}$, oriented normal to the bedding, with an azimuth of $150^{\circ}$, dip $+44^{\circ}$ upwards; d sandy facies from the TT niche, borehole BLT-A8 at a depth of $5.85 \mathrm{~m}$, oriented parallel to the bedding, azimuth $240^{\circ}$, dip $0^{\circ}$ ). Location of the niches are shown in Figure 6 of Bossart et al. (2017a)

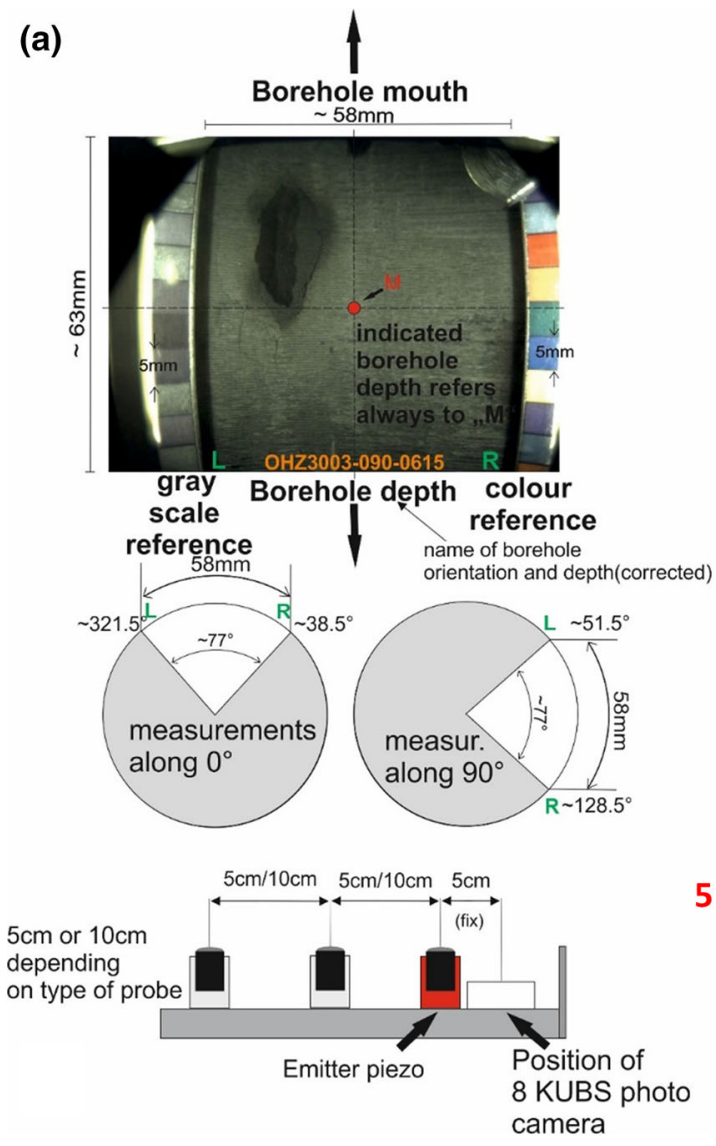

(b)

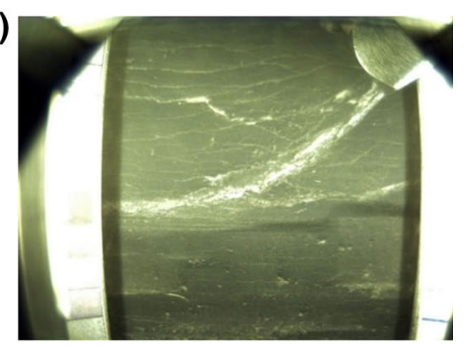

(c)

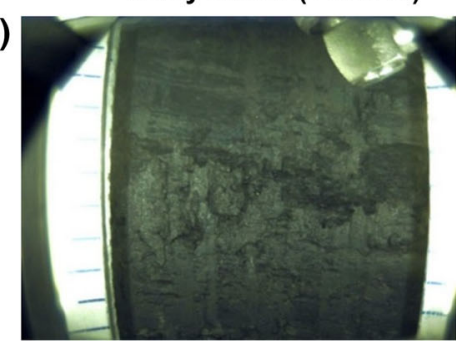

carbonate-rich facies $(9.25 \mathrm{~m})$

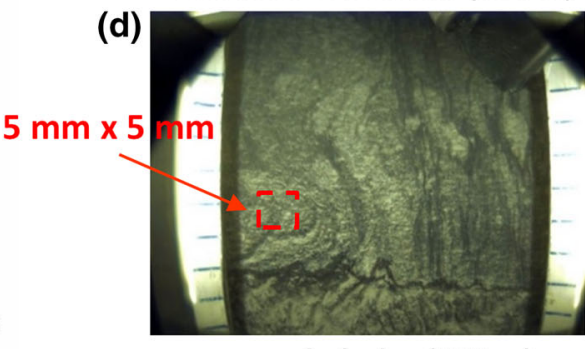

sandy facies $(5.55 \mathrm{~m})$ hanging wall of the Main Fault, penetrating this 1-m-thick fault zone and ending in the footwall at a depth of $16 \mathrm{~m}$. Nicely visible in Fig. 7 are calcite-filled shear-veins within an S- (schistosité) and C (ciscaillement) shear-band. The derived seismic parameters at ca. $12.15 \mathrm{~m}$ clearly confirmed this disturbed structure. 


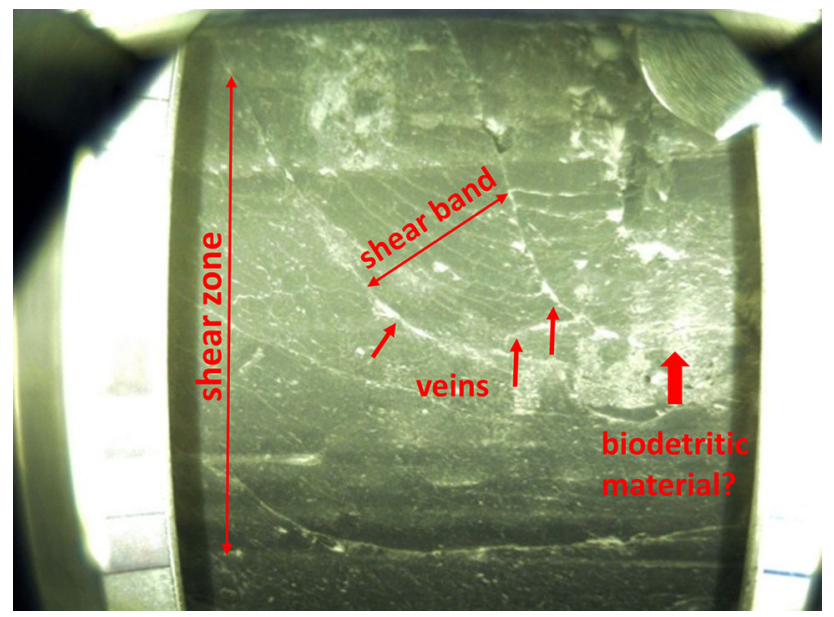

Fig. 7 Borehole camera photograph with small-scale structures from the shaly facies (MI niche, unrolled borehole wall of BSO-37 at a depth of $12.15 \mathrm{~m}$, oriented normal to bedding with azimuth $330^{\circ}$, dip $-40^{\circ}$ downwards, area of $58 \mathrm{~mm}$ by $63 \mathrm{~mm}$ ), showing a highly tectonically deformed zone approximately $6 \mathrm{~m}$ behind the Main Fault, consisting of calcite shear-veins and a S- (schistosité) and C (ciscaillement) shear-band. The location of the MI niche and the Main Fault is shown in Figure 6 of Bossart et al. (2017a)

The high potential of IVM for resolving substantial spatial variations is demonstrated in three examples (see Figs. 8, 9, 10, 11). First, IVM were performed in a 28 -mlong borehole (location: MI niche, drilled $45^{\circ}$ up towards S) running perpendicular to the bedding through three facies of the Opalinus Clay (shaly, carbonate-rich sandy, and sandy). Second, in a 16-m-long borehole (BWS-I2) with identical orientation only a few $\mathrm{m}$ further $\mathrm{W}$, in addition to IVM we also performed geoelectrical and gamma ray measurements. For comparison and discussion of results, see Fig. 10 and text below. For the third example, we show results from a borehole orientated parallel to bedding strike solely within the sandy facies (location: TT niche, drilled horizontally towards $\mathrm{W}$ at the heading face of the TT niche). A further small-scale variability aspect, namely the detection of fractures, is addressed in Sect. 3.3.

In the 28-m-long borehole, BDM-B2, we performed IVM with an 8-channel ultrasonic borehole probe in $5 \mathrm{~cm}$ steps. This resulted in 548 excitation points (CSP) and a total of 4384 seismic traces. Figure 8, representing R4 data (distance of $20 \mathrm{~cm}$ from the emitter), shows a COF section consisting of 548 single $\mathrm{R} 4$ recordings in a colour-coded amplitude point mode display. The data are plotted ensemble-normalized, meaning that the highest amplitude value (corresponding to $100 \%$ ) over the complete seismic section, is used to normalise all other amplitudes. This allows direct comparison of all amplitudes within a section and enables direct observation of seismic energy attenuation along a profile. For example, strong local seismic wave-energy attenuation is mostly related to the occurrence of faults or fractures. It is clear from Fig. 8 that the seismic amplitudes up to $7.5 \mathrm{~m}$ borehole depth are weaker than those at greater distances. Furthermore, several locally confined amplitude attenuations are obvious for example at 5.5, 13.4 and $26 \mathrm{~m}$ borehole depth. The rock between 7.5 and $26 \mathrm{~m}$ borehole depth seems to be more competent than other borehole sections. This is the part of the Opalinus Clay that we interpret as the carbonate-rich sandy and sandy facies.

The derived apparent $v_{p}$ along the total depth for receiver 1 is plotted on Fig. 9 (emitter-receiver distance is $5 \mathrm{~cm}$ ). The app. $v_{p}$ covers a range of about $3000 \mathrm{~m} / \mathrm{s}$. At this receiver 1 , the app. $v_{p}$ is still influenced by the existence of a $\mathrm{BdZ}$ but yields the highest spatial resolution due to the shortest distance between emitter and receiver $\mathrm{R} 1$. Up to $20 \mathrm{~cm}$, the app. $v_{p}$ of the shotcrete is measured, followed by a reduced app. $v_{p}$ within the EDZ. At around $1.5 \mathrm{~m}$ an app. $\mathrm{v}_{\mathrm{p}}$ of $2550 \mathrm{~m} / \mathrm{s}$ for the shaly facies (perpendicular to bedding) starts with a positive anomaly at

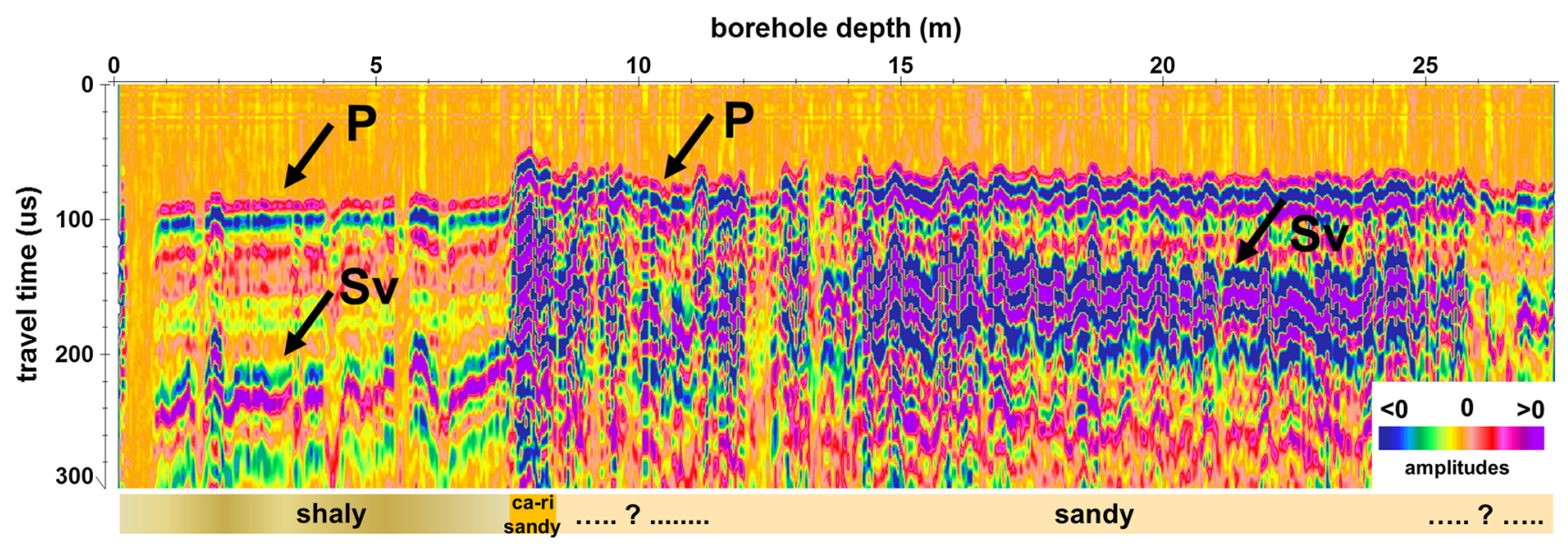

Fig. 8 IVM data from borehole BDM-B2 crossing three facies of the Opalinus Clay. Ensemble-normalised seismic section comprising all traces recorded at a distance of $20 \mathrm{~cm}$ from the emitter (constant offset (COF)) with marked P- and Sv-wave phases. Amplitudes are colour coded 
Fig. 9 Derived apparent $v_{p}$ data from IVM in borehole BDM-B2 (see also Fig. 8) for receiver R1 $(5 \mathrm{~cm})$. The large dynamic range of $v_{p}$ is remarkable. For selected sections, a mean $v_{p}$ is plotted and selected

photographs from the borehole wall are shown. Note the close similarity of $\mathrm{v}_{\mathrm{p}}$ distribution compared with borehole BWSI2, which has the same orientation and is located several meters further $\mathrm{W}$ (Fig. 10)

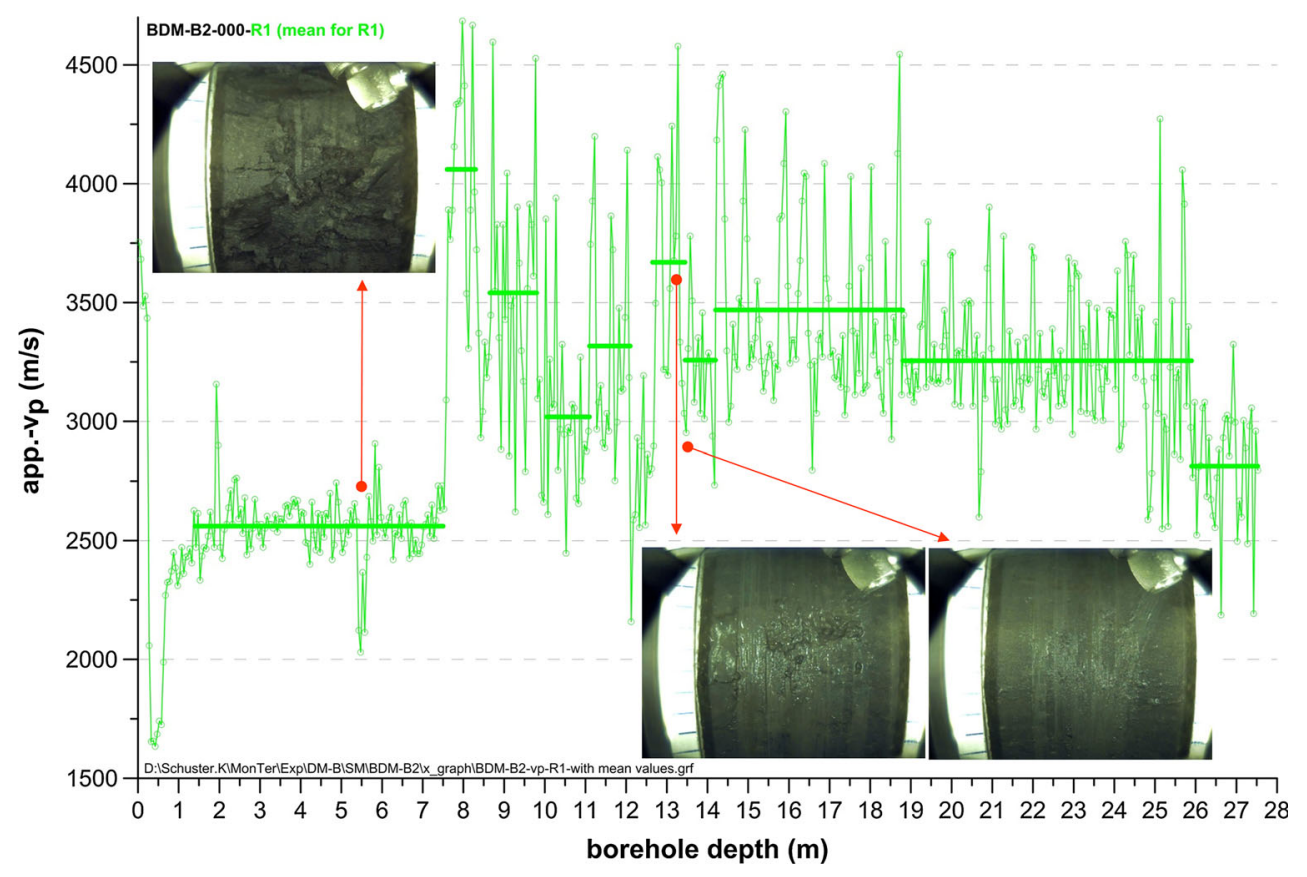

borehole length $(\mathrm{m})$

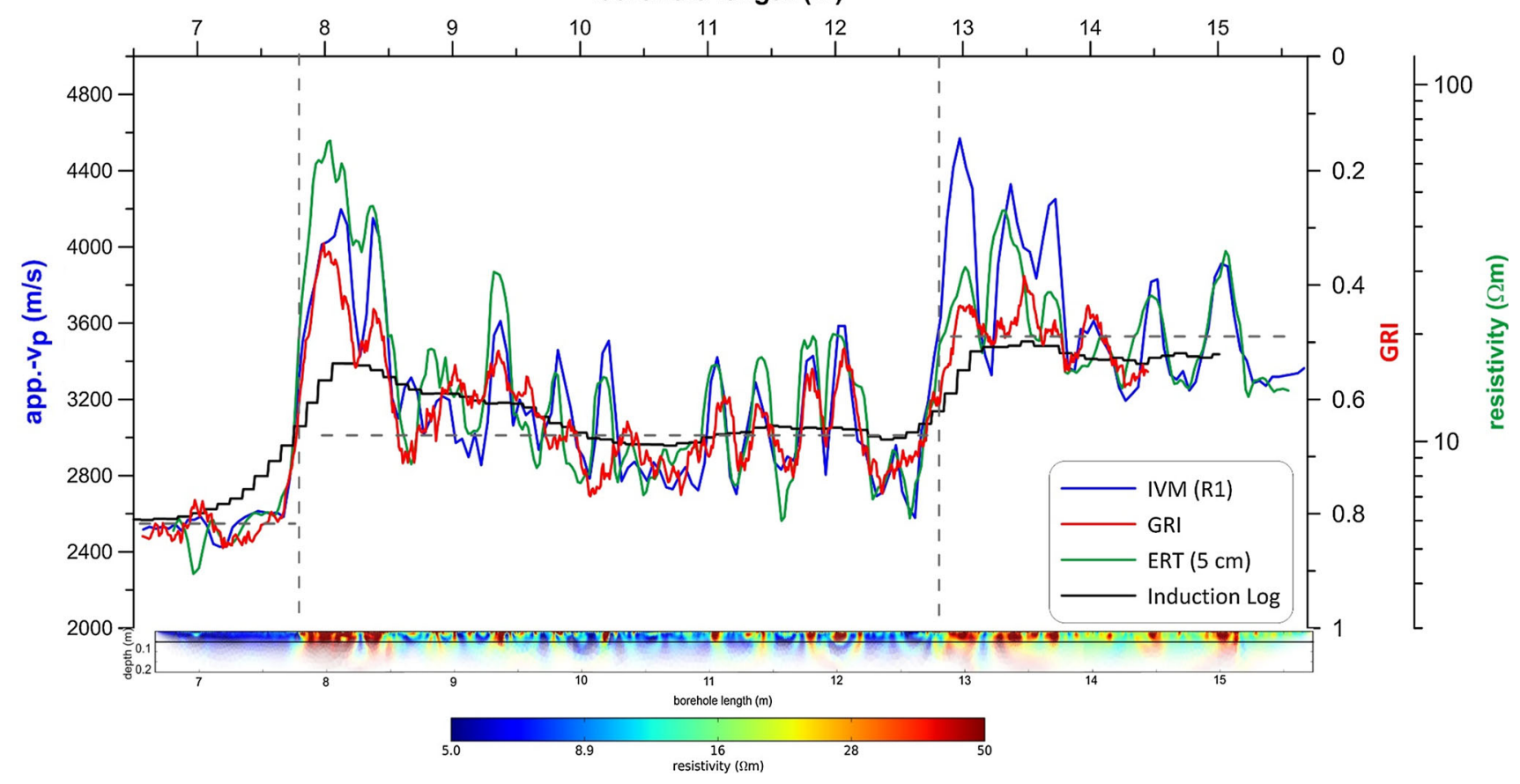

Fig. 10 Comparison of IVM-, ERT-, GRI and conventional induction log data derived in borehole BWS-I2. Note the close similarity of $\mathrm{v}_{\mathrm{p}}$ distribution in comparison with borehole BDM-B2, which has the same orientation and is located several m further E (Fig. 9)

$1.9 \mathrm{~m}$ and a major disturbances at $5.5 \mathrm{~m}$. Very clearly at $7.5 \mathrm{~m}$, the transition into the carbonate-rich sandy facies with an app. $v_{p}$ of $4700 \mathrm{~m} / \mathrm{s}$ can be seen followed by a gradual app. $\mathrm{v}_{\mathrm{p}}$ decrease until $10.5 \mathrm{~m}$, then the app. $\mathrm{v}_{\mathrm{p}}$ varies between 3000 and $4000 \mathrm{~m} / \mathrm{s}$. The continuous app. $\mathrm{v}_{\mathrm{p}}$ periodicity with ups and downs seems to be interrupted/ disturbed at certain depths, e.g., around 10.8, 12.4, 13.7 and
$15.5 \mathrm{~m}$. Slight disturbances at these locations can be seen in the photographs taken during the IVM. Figure 9 shows three representative photographs.

From this distribution of derived app. $v_{\mathrm{p}}$, a distinct transition from the carbonate-rich sandy into the sandy facies can hardly be distinguished. Notable is the app. $v_{p}$ distribution at the end, between 25.9 and $27.5 \mathrm{~m}$, where the 


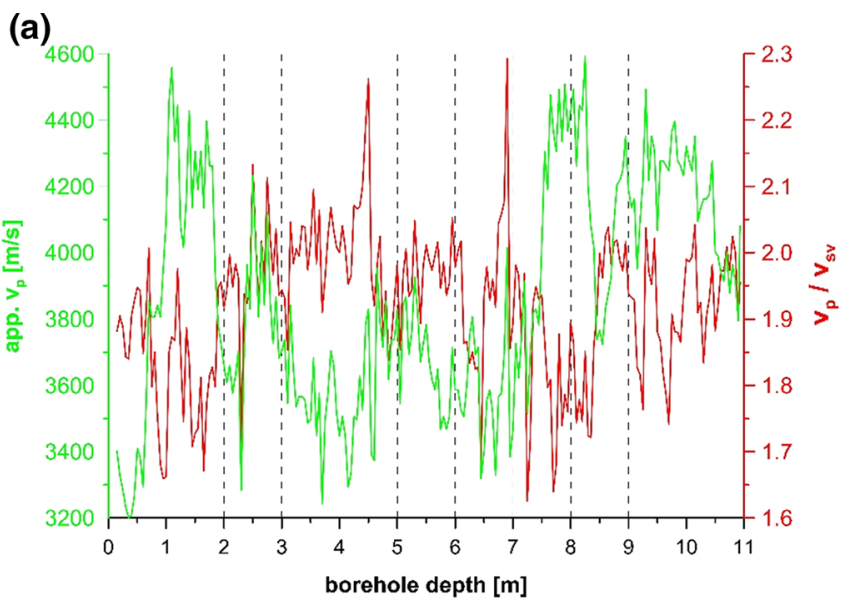

Fig. 11 Derived seismic parameters from IVM in borehole BLT-A8 (sandy facies, parallel with respect to bedding strike) for receiver R4 $(20 \mathrm{~cm})$. a Apparent $\mathrm{v}_{\mathrm{p}}$ (left $y$-axis) and $\mathrm{v}_{\mathrm{p}} / \mathrm{v}_{\mathrm{sv}}$ ratio (right $y$-axis). b

average $v_{p}$ lies somewhere between the mean $v_{p}$ for the shaly and sandy facies. A hand-picked differentiation between different "segments" at the disturbances was made in order to calculate mean app. $v_{p}$ values. These mean values allow for an apparent differentiation within the sandy facies, including the carbonate-rich sandy facies (Fig. 9). The $v_{p}$ distribution appears highly variable. It clearly reflects the known small-scale heterogeneity of the Opalinus Clay. Comparable $\mathrm{v}_{\mathrm{p}}$ distributions are observed in several neighbouring boreholes where the parameter variability is similar.

In the nearby borehole BWS-I2, the $v_{p}$ and specific electrical resistivity distribution could be correlated with clay content interpreted via the derived gamma-ray index distribution (Fig. 10). This $16 \mathrm{~m}$ long borehole begins also in the MI niche only several $\mathrm{m}$ further west at a comparable location (drilled $45^{\circ}$ upwards towards S). A clear correlation was found with high-resolution electrical resistivity tomography measurements (ERT) results. ERT measurements were performed with a BGR borehole probe comprising 50 electrodes at distances of $1.5 \mathrm{~cm}$. Results from an ERT with Wenner- $\alpha$ configuration were inverted and the specific electrical resistivity distribution were taken from the 2D-modell at a depth of $5 \mathrm{~cm}$ for comparison with R1 app. $v_{p}$ data from IVM (same borehole, nearly same orientation of sensors and electrodes). The correlation between the geophysical parameters (IVM and ERT) is very clear, except at some locations where the results are in contrast (e.g., at $8.5 \mathrm{~m}$ ). Such findings must be investigated in more detail. More remarkable is the generally very clear correlation between the gamma-ray index (GRI) and both geophysical parameter distributions. The GRI can be interpreted as a measure of the clay content (GRI $=1$ equates pure clay and GRI $=0$ indicates absence of clay). Higher specific electrical resistivities, which correlate very

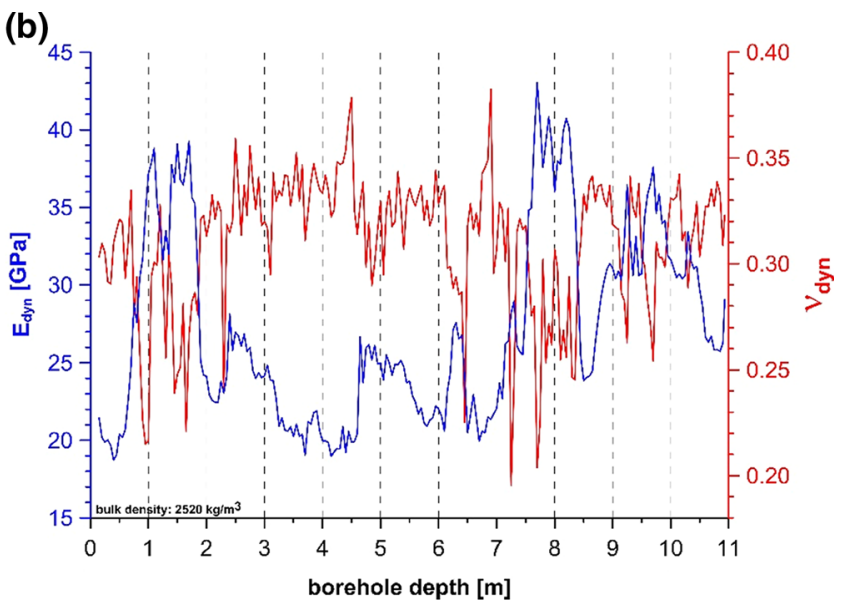

Estimated dynamic Young's modulus (left y-axis) and Poisson's ratio (right $y$-axis)

well with higher $\mathrm{v}_{\mathrm{p}}$, are interpreted to indicated greater contents of carbonates and/or silica (sand) (Furche and Schuster 2015). The general trend of the ERT results is confirmed by results from a conventional induction log performed by a contractor in the same borehole (Fig. 10). Furthermore, comparing $\mathrm{v}_{\mathrm{p}}$ data from borehole BDM-B2 (Fig. 9) with the results discussed here show a clear similarity in the $v_{p}$ distribution. For example, the sharp transition between the shaly facies and the carbonate-rich facies around $7.5 \mathrm{~m}$ is reflected in both representations as well as the individual $v_{p}$ distributions. We interpret this as a characteristic geological structure that can be detected and followed over a larger distance. This indicates that the methods yield repeatable and reliable results and can support stratigraphical site investigations.

The inferred small-scale heterogeneity in app. $v_{p}$ can be directly related to the dynamic elastic parameters, e.g. $\mathrm{E}_{\mathrm{dyn}}$. These spatial heterogeneities must be accounted for when geomechanically characterising such mechanically variable rock packages.

On close analysis, the data from borehole BDM-B2 (Fig. 9) seem to reveal a second phenomenon (e.g., in the depth range 16 to $19 \mathrm{~m}$ ), namely, a periodicity of the app. $\mathrm{v}_{\mathrm{p}}$ distribution. In the related $\mathrm{R} 4$ app. $\mathrm{v}_{\mathrm{p}}$ data, this periodicity is even more clearly quantifiable because the plot is smoother due to the greater emitter-receiver distance of $20 \mathrm{~cm}$. The periodic app. $\mathrm{v}_{\mathrm{p}}$ variation between 3000 and $4000 \mathrm{~m} / \mathrm{s}$ is significant. A full cycle contains between 5 and 10 measuring points corresponding to "wave-lengths" between 0.25 and $0.5 \mathrm{~m}$. Whether this periodicity can be related to sedimentation cycles should to be investigated further.

The third example shows results from an IVM investigation in the sandy facies. The 11-m-long sub-horizontal borehole, BLT-A8, starts at the heading face of the TT- 
niche and was drilled parallel to the bedding strike. The cores show no signs that there is deviation from a parallel to bedding-strike orientation, however, all derived parameters show very strong variations. This is illustrated here by the $\mathrm{R} 4$ data in Fig. 11. The app. $\mathrm{v}_{\mathrm{p}}$ and the app. $\mathrm{v}_{\mathrm{p}} / \mathrm{v}_{\mathrm{sv}}$ ratio is depicted in Fig. 11a. It is important to note the particularly high $\mathrm{v}_{\mathrm{p}}$ and low $\mathrm{v}_{\mathrm{p}} / \mathrm{v}_{\mathrm{sv}}$ ratio between 1 and $2 \mathrm{~m}$, and around $8 \mathrm{~m}$. The derived dynamic Poisson's ratio $v_{\text {dyn }}$ varies between 0.22 and 0.31 in this range and between 0.20 and 0.38 along the total depth range (Fig. 11b). A bulk density of $2520 \mathrm{~kg} / \mathrm{m}^{3}$ was chosen for the calculation of $\mathrm{E}_{\mathrm{dyn}}$. Consequently, the $\mathrm{E}_{\mathrm{dyn}}$ distribution is similar to the derived velocities (Fig. 11b) with three significant local maxima of $E_{d y n}$ at around $1.5,8$ and $9.5 \mathrm{~m}$. The rate of penetration (ROP) during drilling decreased at these depth significantly due to the unexpected high resistance/ strength. Whether the $\mathrm{E}_{\mathrm{dyn}}$ variation with values between 18 and $42 \mathrm{GPa}$ is solely associated with mineralogical variations along the borehole or other changes, such as variability of porosity or different saturation of pore space, requires further investigation. Similar significant beddingparallel variations of seismic parameters was also observed in the 4-m-long borehole BED-C2 drilled from the access gallery into the sandy facies, but with lower minimum and maximum $v_{p}(2600-4000 \mathrm{~m} / \mathrm{s})$.

Summarizing the results of this section: (1) the Opalinus Clay at the Mont Terri rock laboratory can be very heterogeneous in terms of $\mathrm{P}$ - and $\mathrm{S}$-wave velocities and dynamic elastic properties. (2) The scale of these heterogeneities is on the order of $\mathrm{cm}$ to $\mathrm{dm}$ and suggests a layered macro-structure/mechanical stratigraphy. (3) This is particularly relevant when dealing with stress redistributions around tunnels and other excavations where major stress concentration must be anticipated in the stiffer layers.

\subsection{Excavation damaged zones (EDZ) and fracture detection}

Underground excavations inevitably lead to an excavationdamaged/disturbed zone (EDZ/EdZ). If the stresses exceed the strength of the material, an EDZ characterised by fractures and micro-cracks will develop. EDZ are present at the Mont Terri rock laboratory in different forms (Bossart et al. 2017b). IVM is very sensitive to the existence of fractures and micro-cracks and therefore this method is preferentially used to characterise the extent as well as the degree of rock mass perturbation. The method is discussed in Sect. 3.2 (see also Fig. 5). We will now discuss an example from the EZ-B (Fracture Generations) experiment (Yong 2007) performed in the shaly facies. The stepwise excavation of a 5-m-long niche (diameter $3.8 \mathrm{~m}$ ) in the shaly facies of the Opalinus Clay was followed with, amongst other techniques, IVM. The central axis of the EZ-
B niche is oriented normal to the bedding strike. The bedding planes dip $45^{\circ}$. We discuss the first of fifteen IVM repetitions in the central borehole BEZ-B3. This borehole coincides with the central axis of the niche. The first measurements were performed about three months after the excavation of Gallery 04. Figure $12 \mathrm{a}$, b shows the derived $\mathrm{v}_{\mathrm{p}}, \mathrm{v}_{\mathrm{sv}}$ and normalized P-wave onset phase-amplitude distribution along the borehole for a $90^{\circ}$ (3 o'clock) orientation of the piezoelectric transducers, corresponding to $45^{\circ}$ with respect to the bedding planes. The pronounced smallscale variability in all parameters for depths greater than $2 \mathrm{~m}$ reflects the heterogeneity of the rock. It applies also to the dynamic elastic parameters $v_{\text {dyn }}$ and $E_{\text {dyn }}$ that we calculated using BdZ-corrected velocities (Fig. 12c). A comparison of dynamic moduli for depths greater than $6 \mathrm{~m}$ with BHE-25 data (see Fig. 4, both boreholes oriented $45^{\circ}$ with respect to bedding planes) shows that $\mathrm{E}_{\mathrm{dyn}}$ in the sidewall situation (BEZ-B3) is slightly higher than $E_{d y n}$ in the floor derived from BHE-25 data.

The significantly reduced $\mathrm{v}_{\mathrm{p}}$ and $\mathrm{v}_{\mathrm{sv}}$ in the first $1.45 \mathrm{~m}$ and the deviation of the normalized amplitude values from the mean value $(=100 \%)$ are used to determine the extent of the EDZ. In addition, we use several COF section data plots, each ensemble-normalised. The extent of the EDZ derived from seismic parameters, was assessed to be $1.45 \mathrm{~m}$. Shortly after any excavation step, a structural and geological mapping along the side-walls of the niche was performed (Yong et al. 2010). Visual mapping shows the extent of fractures and cracks up to $1.3 \mathrm{~m}$ (left side) and $1.5 \mathrm{~m}$ (right side) as a consequence of the excavation of Gallery 04. Accounting for the variability of the Opalinus Clay and the different mapping and measurement locations, the seismically-derived EDZ extent of $1.45 \mathrm{~m}$ agrees well with the observations. The notch in the $\mathrm{v}_{\mathrm{p}}$ graph at $1.15 \mathrm{~m}$ can be attributed to a higher density of pre-existing fractures (see also Fig. 13).

The degree of damage can be assessed using the degree of deviation, e.g., for $\mathrm{v}_{\mathrm{p}}$, from a known representative mean value for this locality and specific borehole orientation towards bedding; or a mean value estimated from the same measurement, but outside the EDZ and away from major anomalies. Figure $12 \mathrm{~d}$ shows the deviation of the measured values from the mean $v_{p}$ outside the EDZ $(2700 \mathrm{~m} / \mathrm{s})$ starting from $0.25 \mathrm{~m}$ [data from the shotcrete $(0-0.15 \mathrm{~m})$ are excluded]. The plotted data correlates with the intensity of the damage within the EDZ. For distances between 0.15 and $0.25 \mathrm{~m}$ the damage of the rock resulted in a very strong attenuation of signals implying relatively high damage. From $1.5 \mathrm{~m}$ onwards, the deviations are in the range of the estimated standard deviation for the mean $\mathrm{v}_{\mathrm{p}}$, implying relatively low damage. Note the higher values around $1.15 \mathrm{~m}$ that are explained by the $\mathrm{v}_{\mathrm{p}}$-notch discussed above. 
(a)
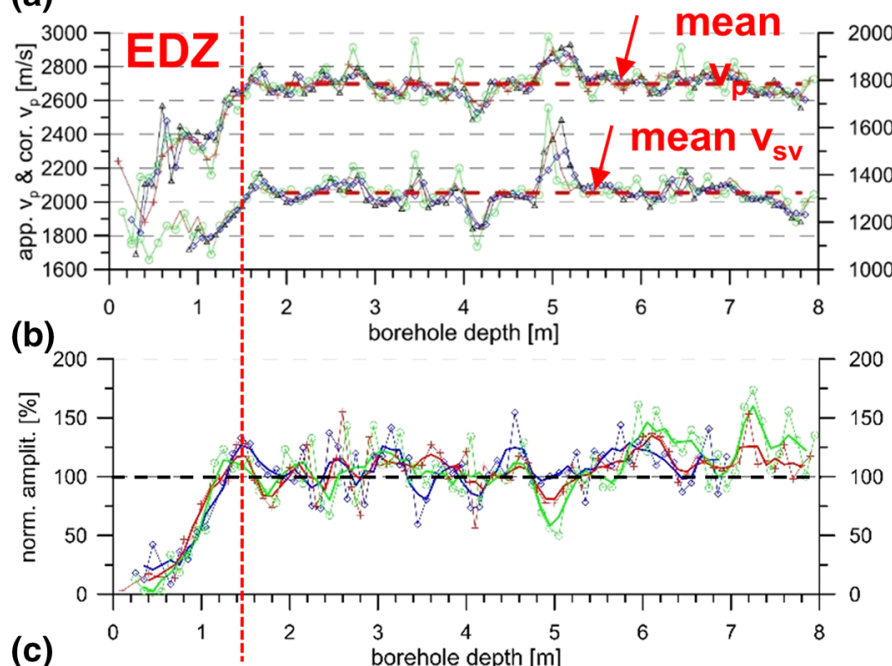

(c) borehole depth $[\mathrm{m}]$

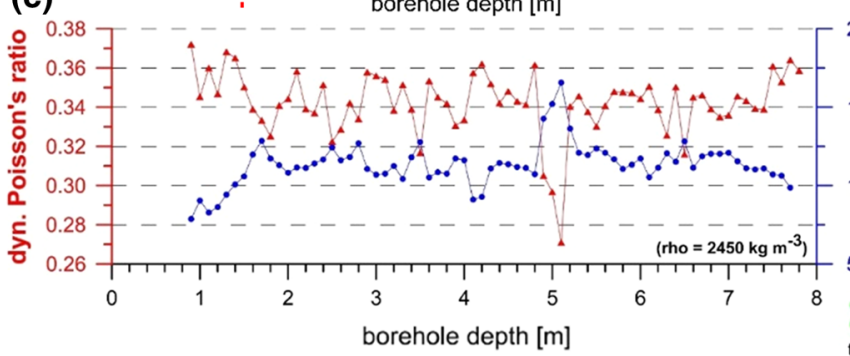

Fig. 12 Derived seismic parameters from first IVM along borehole BEZ-B3. a Apparent $\mathrm{v}_{\mathrm{p}}$ (left y-axis) and $\mathrm{v}_{\mathrm{sv}}$ (right y-axis) distribution for receivers R1, R2 and R3 $(10,20$ and $30 \mathrm{~cm})$ and $B d Z$ corrected $v_{p}$ and $\mathrm{v}_{\mathrm{sv}}$. $\mathbf{b}$ normalised $\mathrm{P}$-wave amplitudes for receivers R1, R2 and R3. The derived extent of the EDZ is marked at $1.45 \mathrm{~m}$. c Dynamic Poisson's ratio (left y-axis) and dynamic Young's modulus (right $y$-axis). Both are derived via BdZ-corrected velocities. d Degree of

The local findings presented in Fig. 12d can be compared with a more general dataset presented in Fig. 12e (Bossart et al. 2017b), where extension fractures were systematically mapped in newly excavated side-wall niches constructed perpendicular to the security gallery (diameter of $5 \mathrm{~m}$ ). The observed fractures in these side-wall niches mirror directly the EDZ of the security gallery. In addition to fracture frequencies, we measured trace lengths and orientations. The fracture frequencies obtained are shown in Fig. 12e, varying between 32 and 0 fractures $/ \mathrm{m}$ in a radial distance from 0 to $2 \mathrm{~m}$ in the tunnel wall. The highest frequencies were observed in the first $70 \mathrm{~cm}$ of the tunnel wall, which corresponds to locations where small gypsum spots were observed on fracture surfaces. This phenomenon is interpreted as an interconnected fracture network in the first $0.5 \mathrm{~m}$ of the tunnel wall, where fractures are filled with air and framboidal pyrites were oxidised to gypsum.

Figure 12e reflects the rock damage/disturbance in terms of extension fractures that were observed and mapped by visual inspection after excavation. In contrast, the mini-seismic results (Fig. 12d) reflect rock alteration
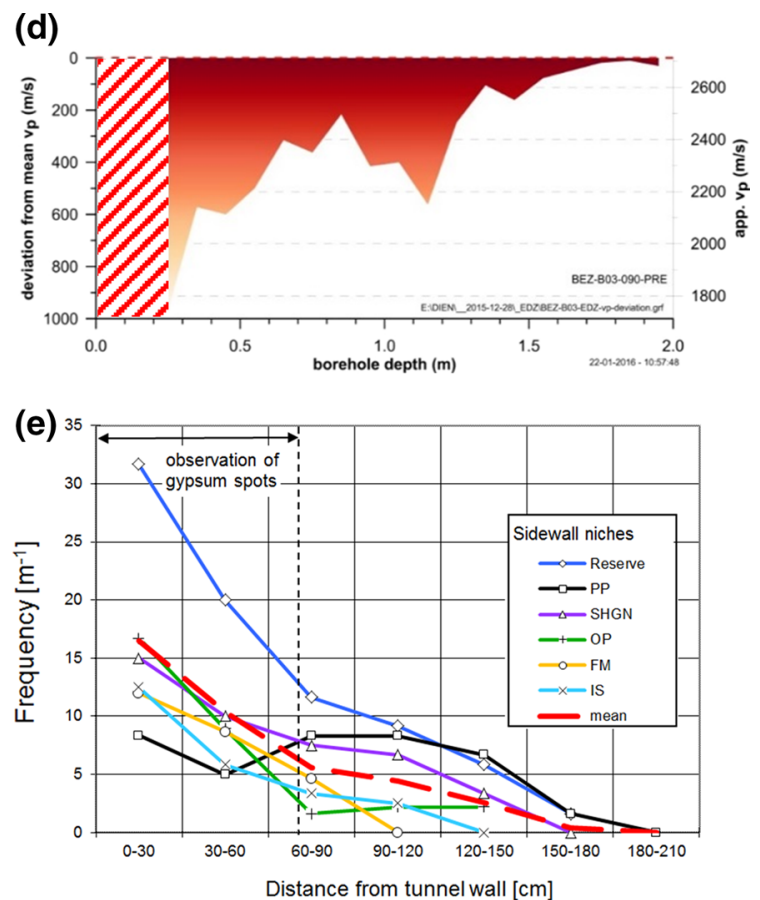

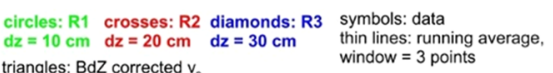

damage within the EDZ calculated as local deviation of $v_{p}$ from a mean reference $v_{p}$. e Fracture frequency in the excavation damaged zones. Extension fractures were mapped by line-counts in newly excavated side-wall niches of the Mont Terri security gallery. Gypsum spots were observed up to $0.7 \mathrm{~m}$ into the tunnel wall of the security gallery, indicating an interconnected fracture network in the first $0.7 \mathrm{~m}$ around the security gallery

caused mainly by fractures at different scales (visible macro- and invisible micro-cracks). Furthermore, at other sites (Schuster 2012) and in other boreholes used for IVM within the EZ-B experiment (Yong 2007), results show very strong seismic-energy attenuation even along visually assessed perfect borehole walls that cannot be explained by visible cracks. We explain this by the existence of microcracks below visual resolution. At several locations from borehole depths of about $0.5 \mathrm{~m}$ onwards, the borehole walls show borehole breakouts in certain orientations. Both plots (Fig. 12d, e) have strong similarities in the extent and the lateral distribution of these features.

We attempted to correlate individual excavation advances with extent of EDZ delineated by the IVM data, but this proved unsuccessful as the excavation rate was found to have no relation. The six excavation steps with advances of $0.58,1.12,0.78,1.32,0.6$ and $0.7 \mathrm{~m}$ resulted in EDZ extents of $0.88,0.59,0.26,1.51,0.96$ and $0.95 \mathrm{~m}$. This was unexpected. Damage ahead of the niche face is best attributed to local relaxation provided by intersecting tectonic shears as well as the proximity to a previously 

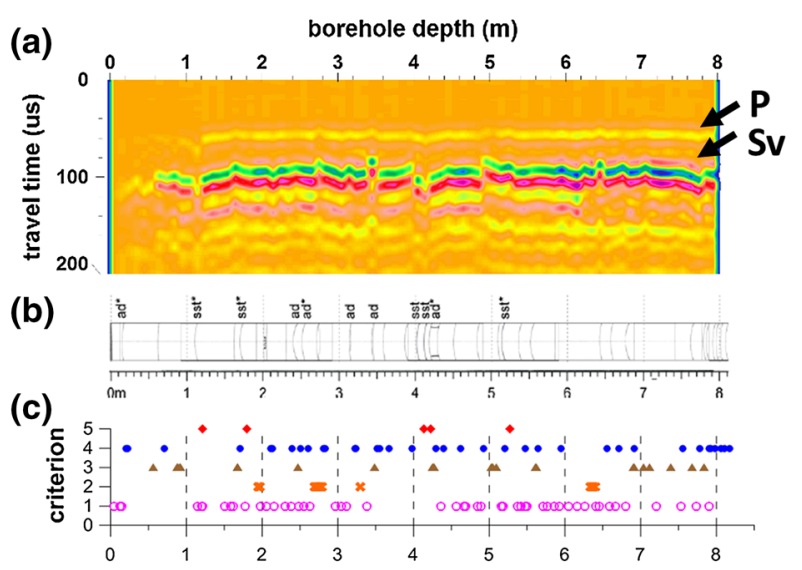

(d)

borehole depth $(\mathrm{m})$

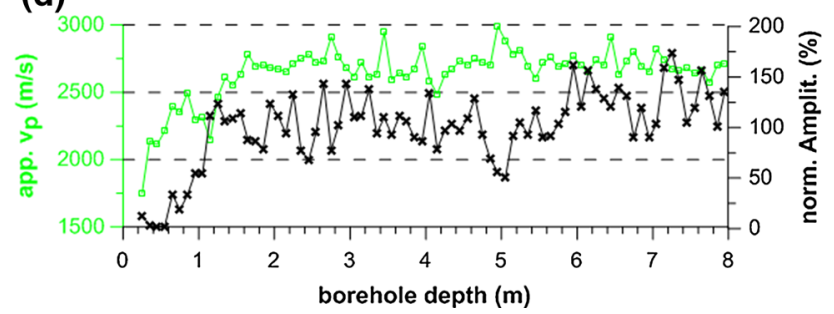

Fig. 13 Comparison of core-mapping attributes with parameters derived from IVM in borehole BEZ-B3. a Seismic COF section (R1 data, ensemble-normalised, amplitudes colour coded). b Core map. c Attributes derived from core mapping, criterion 1 sandy lenses (pink circles), 2 sandy nodules (orange crosses), 3 brownish oxidised lenses, siderite, 4 artificial fractures (blue dots), 5 fractures by way of tectonic structures (red diamonds). $\mathbf{d}$ Apparent $\mathrm{v}_{\mathrm{p}}$ and normalised amplitudes for R1 data

damaged volume of rock due to excavation of an intersecting excavation. Tectonic shears assist in the damage process as they most easily facilitate stress relief, as suggested by the low $\mathrm{v}_{\mathrm{p}}$ and normalized amplitudes near the shears. In Fig. 13, several parameters are summarised that support this explanation.

The ensemble-normalised COF section for receiver R1 data indicates, especially in the Sv-wave phase (Fig. 13a), several anomalies and discontinuities that could result from tectonic structures (i.e., shears and/or fractures). Figure 13b shows a core map and Fig. 13c shows, in more detail, several attributes derived from on-site core mapping. Five clearly identified fractures/tectonic structures (dipping fault plane with striae, criterion 5, red diamonds) at $1.21,1.80,4.14,4.23$ and $5.27 \mathrm{~m}$ and many core features attributed to artificial origins (criterion 4, blue dots) are present. Furthermore, criterion 2 (sandy nodules, orange crosses), criterion 1 (sandy lenses, pink circles) and criterion 3 (brownish oxidised lenses, siderite) are shown. Several of these features correlate well with reduced or higher app. $v_{p}$ or normalised amplitudes (Fig. 13d). The undulations in the app. $\mathrm{v}_{\mathrm{p}}$ and normalised amplitude distributions can be best explained by lateral transitions to sandy lenses or sandy nodules, or to discontinuities. For example, at $1.21,4.14$ and $4.23 \mathrm{~m}$ the fractures (i.e., tectonic shears) found clearly in the cores fit well with reduced app. $v_{p}$ and reduced normalised amplitudes. Further explanations are given in Yong et al. (2013). An uncertainty in the depth location of some $\mathrm{cm}$ has to be taken into account because core removal was not oriented. Furthermore, the IVM borehole data stems from a small location compared with the excavated front of nearly $11 \mathrm{~m}^{2}$.

In summary, the results discussed in this section show that EDZ features are resolved with high spatial resolution with respect to the extent and the degree of damage. Furthermore, fractures and tectonic structures outside the EDZ are detectable.

\subsection{Borehole disturbed zones (BdZ)}

In order to adequately characterise or sample a rock volume, a high density of boreholes is almost always needed. These boreholes themselves may induce significant perturbations in the formation and its response to seismic methods. Experience gained from many measurement campaigns in various underground laboratories where different BdZs have developed has shown that they can be identified using radial velocity gradients deduced from individual apparent velocities derived from IVM. Examples of results from IVM with a 4-channel probe with an apparent $\mathrm{v}_{\mathrm{p}}$ distribution is given in Figs. $4 \mathrm{a}$ and 12a. Three simplified variants of borehole-wall situations are shown in Fig. 14. For differentiation, we use the radial $v_{p}$ distribution. A laterally developed BdZ can clearly be distinguished by the different app. $\mathrm{v}_{\mathrm{p}}$ when compared to an undisturbed borehole wall, which is characterised by a constant $v_{p}$ starting from the borehole wall (Fig. 14a). The most commonly encountered case of $\mathrm{v}_{\mathrm{pR} 1}<\mathrm{v}_{\mathrm{pR} 2}<\mathrm{v}_{\mathrm{pR} 3}$ indicates a positive radial $\mathrm{v}_{\mathrm{p}}$-gradient (Fig. 14b). The rarer "egg-like shell" borehole wall with higher $v_{p}$ near the borehole wall and decreasing $v_{p}$ with distance until the $v_{p}$ of the undisturbed rock is reached is shown in Fig. 14c.

The following example shows how a BdZ changes with time. Drilling of the 29-m-long borehole (location: RC niche, borehole BRC2 drilled horizontally towards SE, orientated at $45^{\circ}$ with respect to bedding strike) was interrupted for operational reasons at $7.2 \mathrm{~m}$. The first IVM was performed immediately after this initial drilling phase. After completing drilling to $29 \mathrm{~m}$, IVM were resumed the next day, starting at $6.5 \mathrm{~m}$ so that the overlapping section between 6.5 and $7.2 \mathrm{~m}$ was measured twice. The quality of both data sets is very good. The derived $\mathrm{v}_{\mathrm{p}}$ are displayed in Fig. 15. Velocities from the first measurement indicate an unusual velocity gradient of $v_{p R 1}>v_{p R 2} \geq v_{p R 3}$ (Fig. 15a) often attributed to a thin high-velocity layer at the borehole wall (egg-like shell). This sort of BdZ could be caused by 
(a)

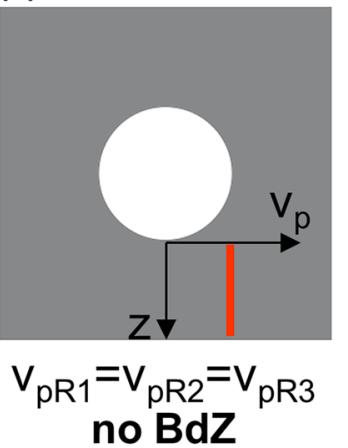

(b)

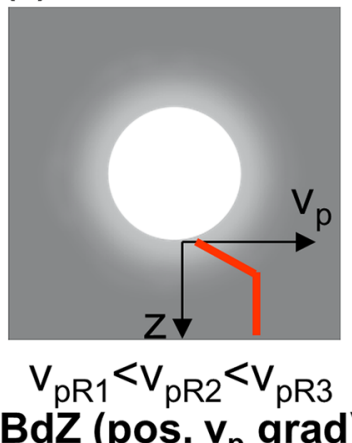

(c)

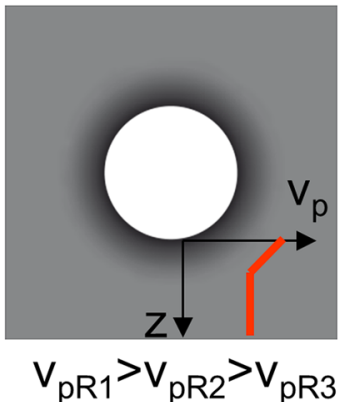

$B d Z$ (neg. $v_{p}$ grad)

Fig. 14 Three simplified variants of a borehole wall characterised by radial $v_{p}$ gradients. a Intact borehole wall, no BdZ. b BdZ with positive $v_{p}$ gradient, the most common case, less competent near the borehole wall. $\mathbf{c} \mathrm{BdZ}$ with negative $\mathrm{v}_{\mathrm{p}}$ gradient, more competent near the borehole wall

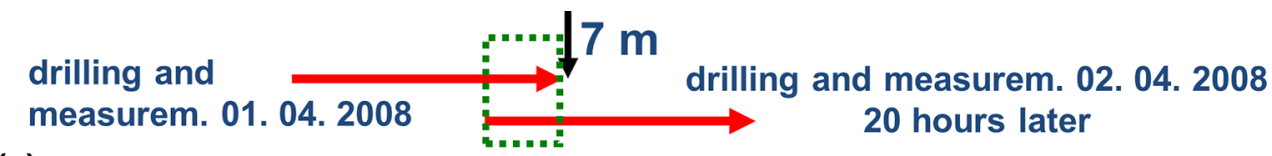

(a) measurem. 01. 04. 2008
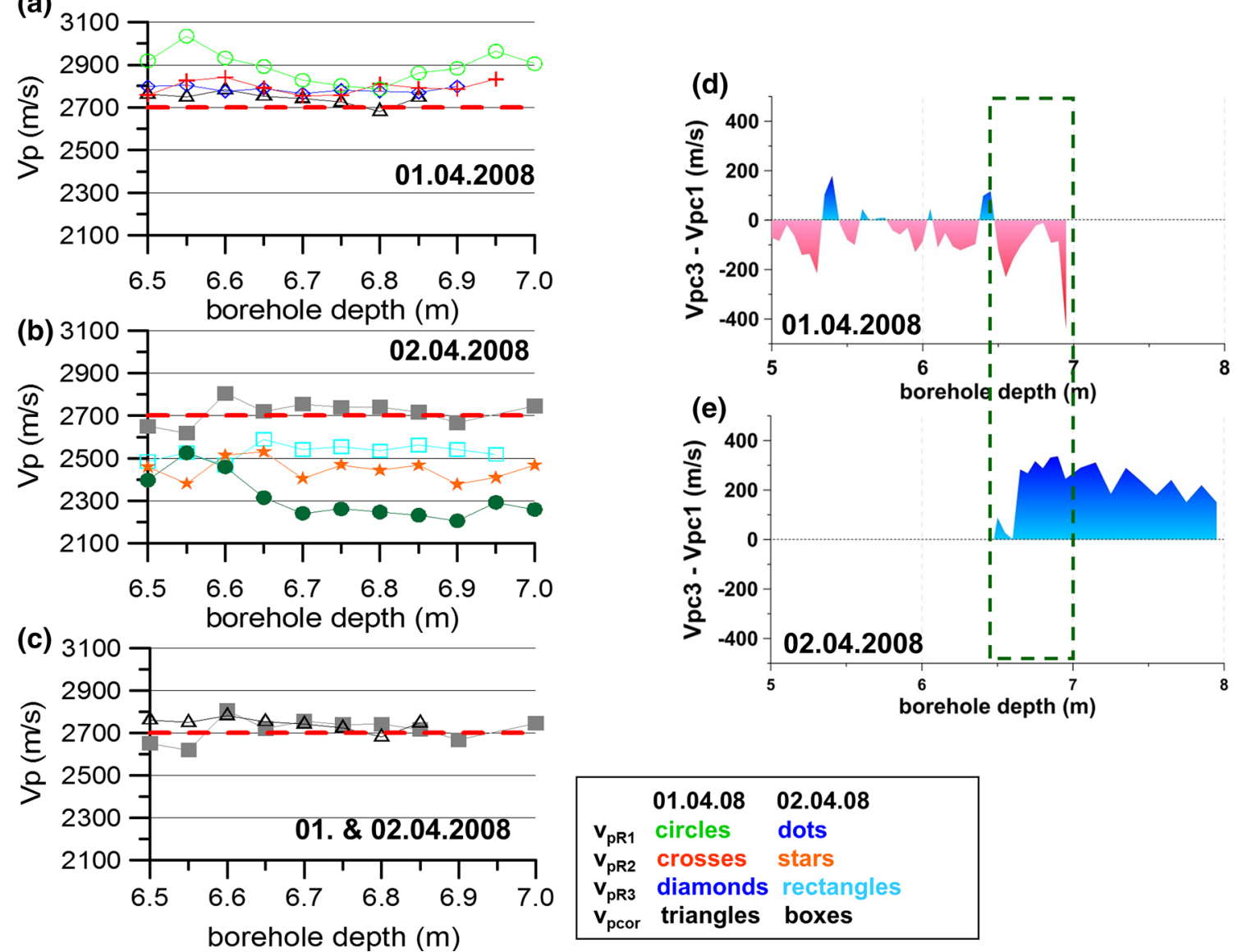

Fig. 15 Evolution of a BdZ derived from IVM in borehole BRC2. Apparent $v_{p}$ distribution for receivers $R 1-R 3$ and $B d Z$ corrected $v_{p}$. a $v_{p R 1}>v_{p R 2} \geq v_{p R 3}$ indicate a negative radial $v_{p}$ gradient (egg-like shell). b Repetition of IVM $20 \mathrm{~h}$ later shows $\mathrm{v}_{\mathrm{pR} 1}<\mathrm{v}_{\mathrm{pR} 2}<\mathrm{v}_{\mathrm{pR} 3}$ the drilling process itself as a result of air drilling, desiccation, and/or increased temperature led to a strengthening of the wall (Wild et al. 2015). The calculated $\mathrm{v}_{\mathrm{p} \text {-corBdz }}$,

indicative of a disturbed borehole wall. $\mathbf{c}$ BdZ corrected $v_{p}$ for both cases are similar. d Qualitative visualisation of the $\mathrm{BdZ}$ via CMP related $\mathrm{v}_{\mathrm{pR} 3}-\mathrm{v}_{\mathrm{pR} 1}$. e As d but $20 \mathrm{~h}$ later

which represents the velocity outside the $\mathrm{BdZ}$, varies around $2700 \mathrm{~m} / \mathrm{s}$, similar to the average value for an undisturbed Opalinus Clay (shaly facies) with a $45^{\circ}$ 
(a)

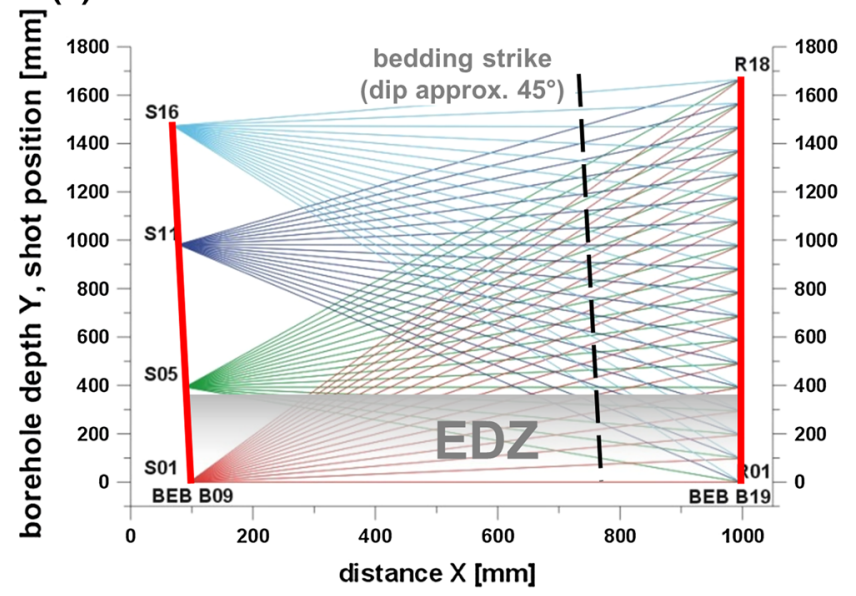

(b)

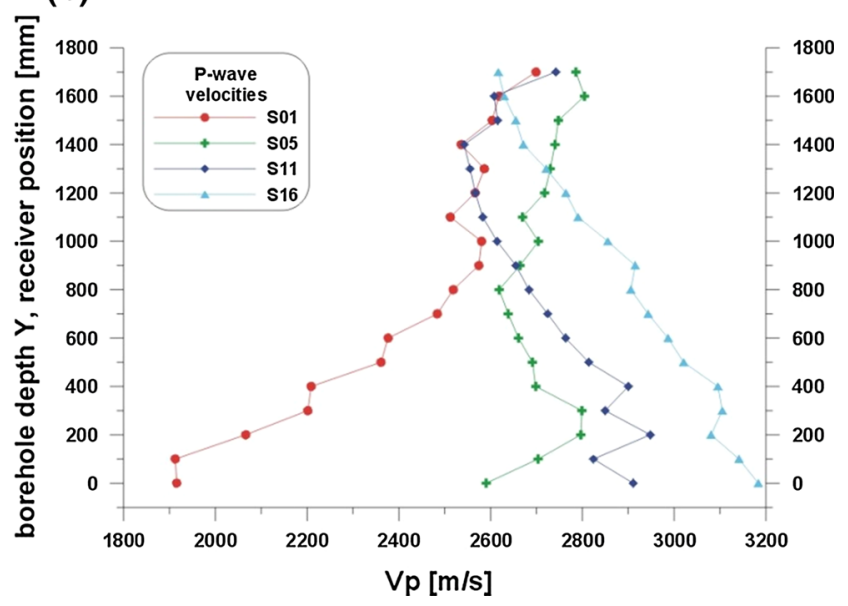

Fig. 16 Seismic anisotropy study between boreholes BEB-B09 and BEB-B19. a Seismic ray-paths for selected emitters and receivers R01-R18. b Derived $\mathrm{v}_{\mathrm{p}}$ distribution for the emitter-receiver combinations shown in a)

borehole orientation towards the bedding planes. Note the similar mean $\mathrm{v}_{\mathrm{p}}$ found in borehole BEZ-B3 for depth greater $2 \mathrm{~m}$ (see Fig. 12a).

The calculated velocity outside the BdZ ( $\left.\mathrm{v}_{\mathrm{p}-\mathrm{corBdz}}\right)$ obtained $20 \mathrm{~h}$ later is in the range of the average value. Both corrected velocities $\left(\mathrm{v}_{\mathrm{p} \text {-corBdz }}\right)$ are very similar in the overlapping section (Fig. 15c). This shows that the correction procedure works well and we are able to "look behind the BdZ". The $v_{p}$ derived from this second measurement show a completely different appearance (Fig. 15b). In this case we observe $\mathrm{v}_{\mathrm{pR} 1}<\mathrm{v}_{\mathrm{pR} 2}<\mathrm{v}_{\mathrm{pR} 3}$, similar to many other measurements, and representing a significant change in the BdZ. The borehole video analysis also revealed a change in the state of the borehole wall. Between 0.8 and $2.7 \mathrm{~m}, 5.4$ and $6.1 \mathrm{~m}$ and 7.0 and $7.2 \mathrm{~m}$, the quality changed from an intact wall to weak sheeting after $20 \mathrm{~h}$. This development is consistent with results reported by Kupferschmied et al. (2015) who investigated the time development of a BDZ around a borehole in the Mont Terri rock laboratory.

Qualitatively, the extent of the BdZ can be visualized by calculating the differences $\mathrm{v}_{\mathrm{pR} 3}-\mathrm{v}_{\mathrm{pR} 1}$ via CMP-related data (Fig. 15d, e). Quantitatively, the extent of the BdZ was calculated for similar data sets using finite-difference raytracing methods (Schuster 2012). From these experimental results, the extent of the $\mathrm{BdZ}$ discussed here varies in the range of several centimeters.

The results discussed in this section show that IVM provides an excellent tool to characterise a $\mathrm{BdZ}$ and its evolution in time.

\subsection{Seismic anisotropy measured in different dimensions}

Anisotropic petrophysical parameters are expected in the Mont Terri rock laboratory due to the fine bedding of the
Opalinus Clay. It is important to quantify these values for subsequent rock-mechanical analyses. Seismic anisotropy directly influences the dynamic elastic performance of rock. We typically assume that the biggest contribution to seismic anisotropy is directly related to bedding orientation (extrinsic or effective portion of the anisotropy) and that the intrinsic portion (mineral fabric and orientation of minerals) is part of the bedding orientation itself. In addition, anisotropy can be influenced by the local stress field. We investigated seismic anisotropy using several different MSM that span a very broad distance range. The smallest are IVM at several $\mathrm{cm}$, then come fan-like crosshole measurements (XHM-F) covering distances of several m, and finally, seismic transmission measurements between drifts (STD) with distances between 10 and $60 \mathrm{~m}$.

From IVM results of the shaly facies and several boreholes with orientations parallel and perpendicular to bedding strike, we deduced a seismic anisotropy coefficient Av. In total, we could use nine boreholes with a normal, and five boreholes with a parallel orientation with respect to the bedding strike. We considered only $\mathrm{v}_{\mathrm{p}}$ values outside the EDZ and not influenced by obviously disturbed borehole regions. The mean $v_{p}$ were $2469 \mathrm{~m} / \mathrm{s}( \pm 51.3 \mathrm{~m} / \mathrm{s})$ for the normal and $3026 \mathrm{~m} / \mathrm{s}( \pm 141.1 \mathrm{~m} / \mathrm{s})$ for the parallel orientations towards bedding planes (standard deviation in parentheses). For the IVM parallel to bedding strike, the sensors were not in all cases aligned along the bedding strike. The estimated seismic anisotropy coefficient $\mathrm{Av}=0.23$.

For the anisotropy analyses with XHM-F, two 1.8-mlong sub-horizontal boreholes at the eastern side-wall of the EB-niche were used (boreholes were drilled $10^{\circ}$ upwards with an orientation nearly parallel to the strike of the bedding). Figure 16a depicts the layout with some seismic ray-paths (Schuster and Alheid 2002). The red 
Fig. 17 Seismic anisotropy in a horizontal plane. Angledependent $v_{p}$ variation of all 576 emitter-receiver combinations in a polar diagram. Note the limited angle coverage. Nevertheless, the data fits well with an elliptical fit, after the EDZ-related $v_{p}$ values were excluded. Four ray coverages are shown as small inserts
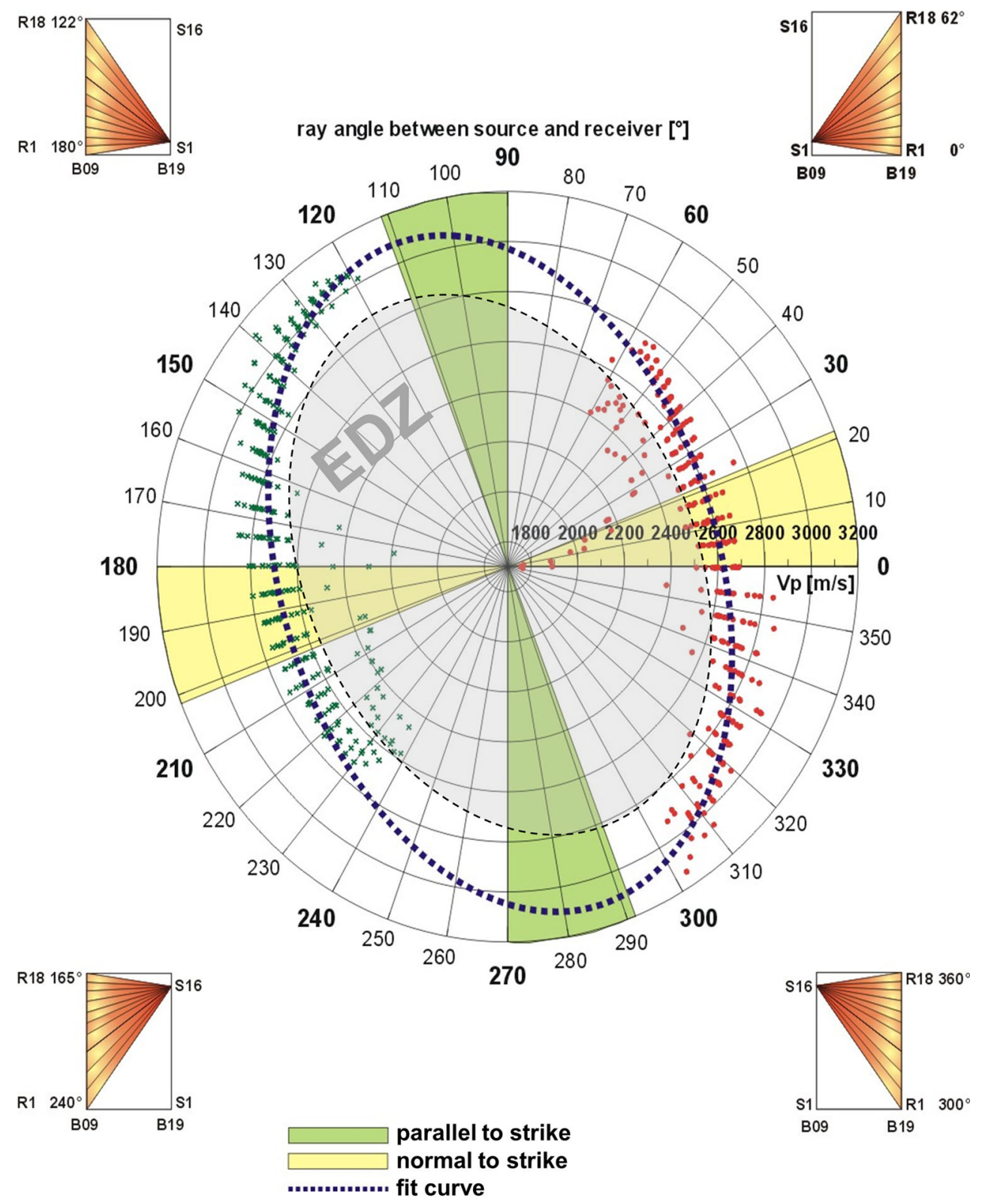

lines represent both boreholes with 16 emitting and 18 receiver positions (left to right). The same array was used in the reverse direction resulting in 576 different ray-paths. Some results are shown in detail in Fig. 16b.

For example, for emitting point S01 (red travel paths) and receiver positions R01-R04, the seismic wave-field travels through the EDZ and nearly perpendicular to bedding. This result in a very low $v_{p}$ of $1900-2200 \mathrm{~m} / \mathrm{s}$. For the other receiver positions (R05-R18), the seismic wave field travels progressively more outside of the EDZ and the angle of incidence with bedding strike extenuate gradually. The $v_{p}$ converges to intermediate values around $2700 \mathrm{~m} / \mathrm{s}$. For emitting point S16, the opposite is true. The compilation of all derived $v_{p}$ is shown as a polar diagram in Fig. 17. The ellipse with violet squares is a simplified fit using only values not influenced by the EDZ. The four small inserts represent selected travel path distributions. The seismic anisotropy coefficient Av derived from this anisotropy ellipse is 0.20 , close to the value obtained from single borehole measurements using IVM.

Finally, we use data from a seismic transmission experiment (ST experiment) for an anisotropy analysis. Fifty piezoelectric 3-component transducers were deployed along the western side-wall of the access gallery (Fig. 18b). Due to the limited number of emitters and receivers and logistical constrains, this is a much more approximate approach to analyse anisotropy compared to the other two methods discussed above. Figure 18a depicts some of the relevant derived $\mathrm{v}_{\mathrm{pz}}$ (z-component) results for three emitting points in Gallery 98 . The numbers $1-50$ 


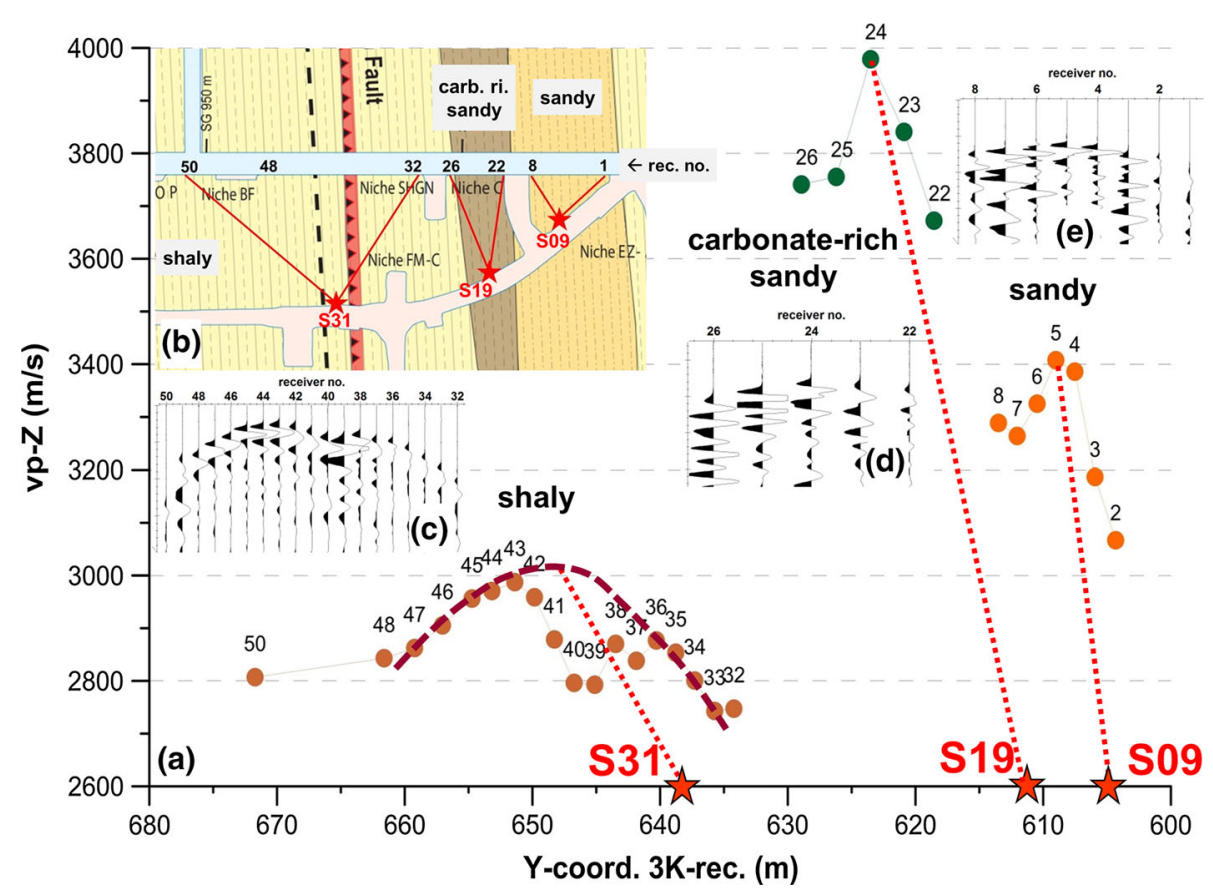

Fig. 18 Results from a seismic transmission experiment were used for an anisotropy study along the three facies types of the Opalinus Clay. a Derived $v_{p z}$ (z-component). The $v_{\mathrm{pz}-\text { max. }}$ direction for each facies is interpreted to be the bedding-strike parallel orientation (sandy facies: $\mathrm{v}_{\mathrm{pz}} \approx 3410 \mathrm{~m} / \mathrm{s}$, carbonate-rich sandy facies: $\mathrm{v}_{\mathrm{pz}} \approx 3990 \mathrm{~m} / \mathrm{s}$ and shaly facies: $\mathrm{v}_{\mathrm{pz}} \approx 3010 \mathrm{~m} / \mathrm{s}$ ). For the shaly

above the dots correspond to the numbering of the $3 \mathrm{~K}$ piezos deployed in the access gallery (Fig. 18b). Emitters and receivers were placed on top of the shotcrete, which is assumed to have thicknesses between 10 and $25 \mathrm{~cm}$. Therefore all derived seismic parameters are influenced by the transition through the intersection and the shotcrete itself. Derived travel times are corrected with an average $v_{p}$ value for shotcrete but the impact is negligible due to the long travel paths $(10-60 \mathrm{~m})$. The bond between shotcrete and Opalinus Clay was assessed via light hammer strokes and rated to be strong enough for good signal transmission.

For clarity, this discussion is limited to emitters and receivers with travel paths running primarily through one of the three known facies of the Opalinus Clay. The high quality of the seismic data is compiled in three inserts (Fig. 18c-e) focusing on first arrival phases. These are ensemble-normalised seismic sub-sections from the three facies. In the sandy and carbonate-rich sandy facies (emitters S09 and $\mathrm{S} 19)$, the highest $\mathrm{v}_{\mathrm{pz}}$ encircled by lower $\mathrm{v}_{\mathrm{pz}}$ is found. This is attributed to the travel path between emitter and receiver with the highest $\mathrm{v}_{\mathrm{pz}}$ coinciding approximately with the orientation of the bedding planes (highest $\mathrm{v}_{\mathrm{pz}}$ parallel to the facies, the $\mathrm{v}_{\mathrm{pz}}$ distribution was disturbed, most probably by the Main Fault. b The ray coverage for emitter positions S09, S19 and S31. Three-component receivers R1-R50 were deployed in the access gallery and some niches. c-e Ensemble-normalised seismic subsections focusing on the first arrival phases for each facies of the Opalinus Clay

bedding planes). In the shaly facies, the $\mathrm{v}_{\mathrm{pz}}$ distribution is more complex with two local maxima. In this case, the seismic wave-field is probably influenced by the Main Fault, resulting in a local $\mathrm{v}_{\mathrm{pz}}$ reduction. In order to find the fastest direction, the $\mathrm{v}_{\mathrm{pz}}$ distribution curve was fitted and the apex was taken as the maximum $\mathrm{v}_{\mathrm{pz}}$ direction.

Due to logistic constraints, we could not span the angular range necessary for high quality results. The maximum aperture that could be measured in the shaly facies under undisturbed conditions was $55^{\circ}$. A range of at least $90^{\circ}$ is necessary to identify the fastest or slowest direction. The seismic anisotropy coefficient Av derived from the $55^{\circ}$ range was extrapolated to the $90^{\circ}$ range by considering local site information and assuming an elliptical anisotropy distribution, similar to that derived nearby at a smaller scale (cf. Figure 17). This analysis resulted likewise in an Av of 0.2, in good agreement with the other results, but with higher uncertainty.

The main result of this section is that we could determine a seismic anisotropy coefficient Av of 0.2 for the shaly facies of the Opalinus Clay using different methods at different scales. 


\section{Conclusions}

We have applied mini-seismic methods (MSM) in situ in the framework of rock-mechanic, geological, and geotechnical site investigations with high spatial and seismic parameter resolution. These methods offer a good set of powerful tools for real in situ site characterisation through seismic parameters. Especially in cases when core extraction fails or laboratory results are unsatisfactory, MSM are very beneficial to obtain rock properties that can be attributed to real in situ properties. The rock mass can be characterised over scales of several $\mathrm{cm}$ to several dekametres. Even when boreholes are required for high resolution and the drilling can disturb the surroundings, we can correct for these affects. MSM can resolve the heterogeneity of the Opalinus Clay in the $\mathrm{cm}$ range, supporting structural interpretation. We derived a number of seismic and dynamic elastic parameters that are appropriate for rock characterisations. Furthermore, we could establish a relation between the static and dynamic Young's modulus and quantify seismic anisotropy at different scales. It was also possible to resolve small-scale variations within the Opalinus Clay. We investigated EDZ features, including extent and degree of damage, and could characterise the evolution of BdZ with seismic parameters. Furthermore, fractures outside the EDZ are detectable with these seismic methods. The size of the rock volume investigated ranges from several $\mathrm{cm}$ up to several dam. Depending on the desired spatial resolution, non-destructive measurements are performed along or between drifts, between boreholes, or within a single borehole. MSM can therefore accurately capture local in situ conditions for a rock characterization, particularly when the effects resulting from EDZ and BdZ features can be excluded or corrected.

The concepts and applications presented here include many examples that illustrate the power of the techniques and their consistency in the obtained results. Similar results have been gained from measurements that BGR has performed at other locations within the Mont Terri rock laboratory and elsewhere.

Improvements in the techniques are certainly possible; we expect the forthcoming use of 3-component seismic mini-vibrators and 3-component receivers will yield further interesting findings. For a better understanding of the relationship between static and dynamic elastic parameters, controlled experiments that take, for example, porosity and pore-space saturation into account, are necessary. Furthermore, the parallel application of other geophysical methods, as partly demonstrated here, will continue to enhance the interpretations.

Acknowledgements Over the years many colleagues participated in development and measurements. Many thanks to (in alphabetical order): Hendrik Albers, Hans-Joachim Alheid, Dieter Böddener, Christoph Czora, Werner Hökendorff, Peter Eichhorn, Friedhelm Schulte, Wilfried Stille and Torsten Tietz. We thank colleagues from swisstopo, Christophe Nussbaum, David Jaeggi, Thierry Theurillat and Senecio Schefer, for their straightforward local site support. We also thank both reviewers, Till Popp (IFG Leipzig) and Pierre Dick (IRSN Fontenay-aux-Roses), for their very helpful concerted comments that improved the paper. Roy Freeman reviewed the English for readability. Research leading to the results presented here has received funding from the German Federal Ministry of Economics and Energy.

Open Access This article is distributed under the terms of the Creative Commons Attribution 4.0 International License (http://crea tivecommons.org/licenses/by/4.0/), which permits unrestricted use, distribution, and reproduction in any medium, provided you give appropriate credit to the original author(s) and the source, provide a link to the Creative Commons license, and indicate if changes were made.

\section{References}

Bock, H. (2002). RA experiment: Rock mechanics analyses and synthesis: conceptual model of Opalinus clay. Mont Terri Technical Report, TR 01-03. Federal Office of Topography (swisstopo), Wabern, Switzerland. www.mont-terri.ch.

Bossart, P., Bernier, F., Birkholzer, J., Bruggeman, C., Connolly, P., Dewonck, S., Fukaya, M., Herfort, M., Jensen, M., Matray, J-M., Mayor, J. C., Moeri, A., Oyama, T., Schuster, K., Shigeta, N., Vietor, T., \& Wieczorek, K. (2017a). Mont Terri rock laboratory, 20 years of research: introduction, site characteristics and overview of experiments. Swiss Journal of Geosciences, 110. doi:10.1007/s00015-016-0236-1 (this issue).

Bossart, P., Nussbaum, C., \& Schuster, K. (2017b). Generation and self-sealing of the excavation-damaged zone (EDZ) around subsurface excavation in a claystone. Wiley (submitted).

Bossart, P., \& Thury, M. (2008). Mont Terri Rock Laboratory. Project, Programme 1996 to 2007 and Results. Reports of the Swiss Geological survey No. 3. Federal Office of Topography (swisstopo), Wabern, Switzerland. www.mont-terri.ch.

Corkum, A. G. (2006). Non-linear behavior of Opalinus Clay around underground excavations. Ph.D. dissertation, University of Alberta, Edmonton, Alberta, Canada.

Furche, M., \& Schuster, K. (2015). Neuartige Kombination von Geoelektrik (ERT)- und Miniseismik-Messungen zur Charakterisierung von Tongesteinen erfolgreich getestet. BGR online: http://www.bgr.bund.de/DE/Themen/Endlagerung/Methoden/ In_situ/neuartige_kombination_ert_miniseismik_messungen. html?nn=1550002.

Göbel, I., Alheid, H.-J., Alonso, E., Ammon, Ch., Bossart, P., Bühler, C., Emmerich, K., Fernandez, A. M., García-Siñeriz, J. L., Graf, A., Jockwer, N., Kaufhold, St., Kech, M., Klubertanz, G., Lloret, A., Mayor, J. C., Meyer, T., Miehe, R., Muñoz, J. J., Naumann, M., Nussbaum, C., Pletsch, T., Plischke, I., Ploetze, M., Rey, M., Schnier, H., Schuster, K., Sprado, K., Trick, T., Weber, H., Wieczorek, K., \& Zingg, A. (2007). Heater Experiment: rock and bentonite thermo-hydromechanical (THM) processes in the near field of a thermal source for development of deep underground high level radioactive waste repositories. In P. Bossart, \& C. Nussbaum (Eds.), Mont Terri Project-Heater experiment, engineered barriers emplacement and ventilation tests. Reports of the Swiss Geological Survey No. 1 (pp. 7-16). Federal Office of Topography (swisstopo), Wabern, Switzerland. www.mont-terri.ch. 
Jaeggi, D., Laurich, B., Nussbaum, C., Schuster, K., \& Connolly, P. (2017). Tectonic structure of the "Main Fault" in the Opalinus Clay, Mont Terri rock laboratory (Switzerland). Swiss Journal of Geosciences, 110. doi: 10.1007/s00015-016-0243-2 (this issue).

Kupferschmied, N., Wild, K. M., Amann, F., Nussbaum, C., Jaeggi, D., \& Badertscher, N. (2015). Time-dependent fracture formation around a borehole in a clay shale. International Journal of Rock Mechanics and Mining Sciences, 77, 105-114.

Schuster, K. (2002). Seismic in situ Methods for the Characterisation of Excavation Damaged Zones-Final Report. Projektträger des $\mathrm{BMBF}$ und BMWi für Wassertechnologie und Entsorgung, Contract-No. 02E9098.

Schuster, K. (2012). Detection of borehole disturbed zones and small scale rock heterogeneities with geophysical methods. In Proceedings of the EC-TIMODAZ-THERESA International Conference, Impact of thermo-hydro-mechanical chemical (THMC) processes on the safety of underground radioactive waste repositories (pp. 135-145). Luxembourg.

Schuster, K., \& Alheid, H.-J. (2002). Engineered Barrier (EB) Experiment and Geophysical Characterisation of the Excavation Disturbed Zone (ED-C) Experiment: Seismic Investigation of the EDZ in the EB niche. Mont Terri Technical Report, TR 02-03. Federal Office of Topography (swisstopo), Wabern, Switzerland. www.mont-terri.ch.
Schuster, K., Alheid, H.-J., \& Böddener, D. (2001). Seismic investigation of the excavation damaged zone in Opalinus Clay. Engineering Geology, 61, 189-197.

Wieczorek, K., Gaus, I., Mayor, J. C., Schuster, K., García- Siñeriz, J-L., \& Sakaki, T. (2017). In-situ experiments on bentonitebased buffer and sealing materials at the Mont Terri rock laboratory (Switzerland). Swiss Journal of Geosciences, 110. doi:10.1007/s00015-016-0247-y (this issue).

Wild, K. M., Wymann, L. P., Zimmer, S., Thoeny, R., \& Amann, F. (2015). Water retention characteristics and state-dependent mechanical and petro-physical properties of a clay shale. Rock Mechanics and Rock Engineering, 48, 427-439.

Yong, S. (2007). A three-dimensional analysis of excavation-induced perturbations in the Opalinus Clay at the Mont Terri Rock Laboratory, Ph.D. dissertation, Swiss Federal Institute of Technology, Zürich, Switzerland.

Yong, S., Kaiser, P. K., \& Loew, S. (2010). Influence of tectonic shears on tunnel-induced fracturing. International Journal of Rock Mechanics and Mining Sciences, 47, 894-907.

Yong, S., Kaiser, P. K., \& Loew, S. (2013). Rock mass response ahead of an advancing face in faulted shale. International Journal of Rock Mechanics and Mining Sciences, 60, 301-311. 